\title{
Declive y muerte de los frailejones en los ecosistemas alpinos de los Andes del Norte: Modelo Conceptual
}

\author{
Decline and death of Espeletia species in the tropical alpine \\ ecosystem of the Northern Andes: A conceptual model
}

\section{PREPRINT}

\section{Artículo de Revisión Crítica}

Oscar Burbano-Figueroa ${ }^{1,2}$, Eliana Galindez-Chicaíza ${ }^{3}$, Alfonso Javier Benítez-Arteaga ${ }^{3}$, Angela Vanessa Alvarez Coral $^{3}$, Carlos Arturo Florez Casanova ${ }^{4}$, Carlos Arturo Betancourth- García ${ }^{4}$, Claudia Salazar -González ${ }^{4}$, Arturo David-Figueroa $^{5}$, y Luz Estela Lagos Mora ${ }^{3 *}$

\section{Resumen}

Introducción: Los ecosistemas alpinos en el trópico son islas en las alturas, ambientes sin continuidad espacial ubicados a altitudes de más de 3000 - $5000 \mathrm{msnm}$, entre la línea de bosque y la línea de nieves perpetuas. Los ecosistemas alpinos tropicales de mayor extensión y riqueza se encuentran distribuidos en las regiones montañosas ecuatoriales de Sudamérica, África Oriental y Nueva Guinea. Estos ecosistemas son dominados en cada continente por plantas de rosetas gigantes de varias especies vegetales no relacionadas filogenéticamente. Esta extraña arquitectura vegetal es el resultado de la adaptación al proceso diario de congelamiento y descongelamiento que ocurre en los hábitats alpinos tropicales y que ha resultado en convergencia evolutiva. En los Andes, estos ecosistemas han recibido el nombre de páramos. En la última década se han reportado problemas fitosanitarios en especies del género Espeletia, despertado el interés por comprender la causa o causas de estas afectaciones y desarrollar estrategias de manejo y control de los posibles patógenos involucrados.

Objetivo: Desarrollar un modelo conceptual que recolecta, organiza y combina el conocimiento (conceptos e hipótesis propuestas) relacionado con la muerte y declive de los frailejones en las ecosistemas alpinos tropicales de los Andes del Norte. Este análisis permite identificar las brechas de conocimiento actuales para este problema, las hipótesis propuestas para explicarlo y un marco conceptual para el desarrollo de las estrategias futuras de monitoreo y manejo de estas afectaciones.

Materiales y métodos: Mediante la realización de un modelo conceptual se desarrolló una representación funcional del declive y la muerte de frailejones en los Andes del Norte. Esta representación incluye hipótesis presentadas previamente que incorporan interacciones de poblaciones de Espeletia con plagas y patógenos.

Resultados y discusión: El modelo conceptual desarrollado presenta tres hipótesis que describen las interacciones de los frailejones con otros agentes biológicos relacionados con problemas sanitarios reportados

\footnotetext{
${ }^{1}$ Center for Development Research (ZEF), University of Bonn, Genscherallee 3, D-53113 Bonn, NRW, GERMANY

${ }^{2}$ The Plant Interactions Laboratory, Centro de Investigación Turipaná, Corporación Colombiana de Investigaciones Agropecuarias (AGROSAVIA), Km 13 Via Monteria - Cereté, 230558 Cereté, Córdoba, COLOMBIA

${ }^{3}$ Genética y Evolución de Organismos Tropicales (GENPAT), Universidad de Nariño, Calle 18 Carrera 50-Torobajo, 52001 Pasto, Nariño, COLOMBIA

${ }^{4}$ Sanidad Vegetal (GRISAV), Universidad de Nariño, Calle 18 Carrera 50-Torobajo, 52001 Pasto, Nariño, COLOMBIA

${ }^{5}$ AVAnalytics, FLY88613, Gainesville, FL, USA

* Autor de correspondencia: Luz Estela Lagos Mora, email: luzestela@udenar.edu.co, modeloespeletia@gmail.com
} 
previamente. Adicionalmente, provee una descripción de los factores que moldean estas interacciones, principalmente el cambio climático y su efecto sobre la distribución de las plantas del páramo.

Conclusiones: Hasta el momento, los trabajos que han intentado explicar las afectaciones observadas en el género Espeletia, son acciones aisladas para describir y relacionar los síntomas de herbivoría, daño foliar y muerte en pie. Estas observaciones deben ser explicadas en un marco más amplio que permita establecer su rol en el declive y muerte de los frailejones. Adicionalmente, estas infestaciones de plagas y enfermedades deben ser consideradas en los modelos de predicción de desplazamiento que sufrirán las poblaciones de Espeletia como resultado del cambio global. Estas interacciones pueden exacerbar el efecto del cambio climático e incrementar los riesgos de reducción de la población y extinción.

\section{Introducción}

Los ecosistemas alpinos en el trópico son islas en las alturas, ambientes discontinuos ubicados a altitudes de más de 3000 - $5000 \mathrm{msnm}$, entre la línea de bosque y la línea de nieves perpetuas. La línea de bosque es la altura máxima a la cual los árboles pueden crecer. Los ecosistemas alpinos tropicales de mayor extensión y riqueza se encuentran distribuidos en las regiones montañosas ecuatoriales de Sudamérica, África Oriental y Nueva Guinea (Luteyn et al., 1999; Sklenář et al., 2014). Estos ecosistemas son dominados en cada continente por plantas de rosetas gigantes de varias especies vegetales no relacionadas filogenéticamente. Esta extraña arquitectura vegetal es el resultado de la adaptación al proceso diario de congelamiento y descongelamiento que ocurre en los hábitats alpinos tropicales y que ha resultado en convergencia evolutiva (Halloy, 1983; Rundel et al., 1994)

En Sudamérica, los Andes se extienden $8.500 \mathrm{~km}$, desde el extremo sur de Sudamérica, en Argentina, hasta la margen sur del Caribe colombiano y venezolano. Se dividen en tres segmentos latitudinales: sur, centro y norte. Los Andes del Norte están comprendidos entre el oeste de Venezuela y el norte de Perú, en los territorios de Venezuela, Colombia y Ecuador (Bayona, 2018). Los ecosistemas tropicales alpinos de los Andes del Norte se denominan páramos distribuidos entre 3.200 y 4.100 msnm (Figura 1) (Cuatrecasas, 1958; Rangel O., 2000). Se caracterizan por la presencia de humedales y turberas (Hofstede et al. 2003), con vegetación achaparrada adaptada a un ambiente xerofítico y frío (Vásquez et al. 2011). El clima es muy variable y la temperatura fluctúa entre $4^{\circ} \mathrm{C}$ y $8^{\circ} \mathrm{C}$ (Rangel-Ch, 2000). Son entornos cruciales por su facultad para retener y acumular agua, fijar grandes cantidades de carbono atmosférico y además son albergue de especies de fauna y flora características y muchas veces únicas (Llambí et al. 2012).

\section{Distribución de los páramos en los Andes del Norte}

En Colombia se encuentran las mayores extensiones de páramo con una superficie aproximada de 1'932.987 hectáreas representando el 1,7\% del territorio continental. Este país cuenta con más de 300 páramos zonales y azonales sin contar cientos que por su reducida extensión no son registrados e incluidos en inventarios e investigaciones. Los páramos colombianos están principalmente agrupados en las siguientes localidades: Cordillera oriental, cordillera central, cordillera occidental, sector Nariño-Putumayo y sector Sierra Nevada de Santa Marta. Estos a su vez se dividen en quince distritos y treinta y tres complejos (Hofstede et al., 2014; Morales et al., 2007).

En Ecuador estos biomas comprenden un área de 1'337.119 hectáreas aproximadamente representando el 5\% del territorio nacional y el 39,8\% del territorio total, ubicándose a lo largo de las cordilleras Oriental y Occidental de los Andes. Se extienden desde el límite con Colombia al norte hasta el límite con Perú al Sur (Serrano \& Galárraga, 2015). Estos ecosistemas se encuentran distribuidos mayormente en las provincias del Carchi, Cañar, Azuay, Chimborazo, Pichincha y Loja (Beltrán et al., 2009; Hofstede et al., 2014, 2003) 
En Venezuela, los ecosistemas paramunos ocupan una superficie de casi 266.000 hectáreas distribuidas principalmente en el estado de Mérida correspondiendo al 75\% del área total. Los restantes se distribuyen en forma aislada constituyendo un verdadero archipiélago en los estados Táchira y Trujillo con pequeñísimas extensiones en los estados Barinas, Portuguesa y Lara (Llambí, 2015).

En la última década, reportes de afectaciones por insectos y patógenos, y muerte repentina (muerte en pie) de varias especies de frailejones han sido registradas en Colombia, Ecuador y Venezuela (Figura 2). Múltiples hipótesis han sido propuestas por varios grupos de investigación que trabajan en explicar el declive de las poblaciones de frailejones, pero hasta el momento no se ha hecho un intento de compilar, discutir y contrastar este conocimiento e hipótesis. En este contexto, el objetivo de este estudio es desarrollar un modelo conceptual que recolecta, organiza y combina el conocimiento (conceptos e hipótesis propuestas) relacionadas con la muerte y declive de los frailejones en las ecosistemas alpinos tropicales de los Andes del Norte. Este análisis permite identificar las brechas de conocimiento actuales para este problema, las hipótesis propuestas para explicarlo y las estrategias futuras para encontrar una solución.

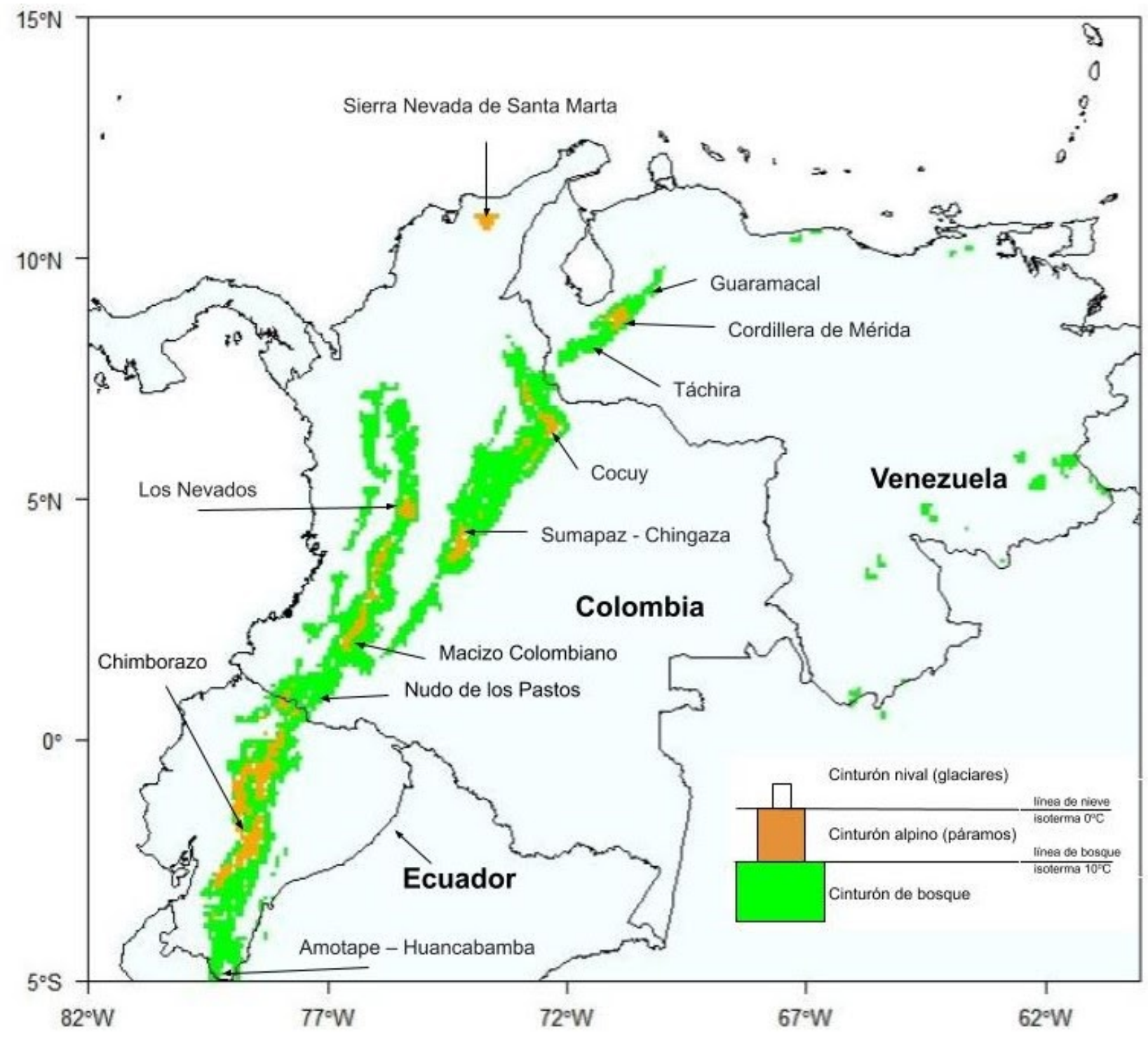

Figura 1. Distribución de cinturón de ecosistemas alpinos (páramos) en Ecuador, Colombia y Venezuela. Estos fueron estimados usando la definición de zonas climáticas Köppen-Geiger (Kottek et al., 2006; Rubel et al., 2017). 


\begin{tabular}{|c|c|c|}
\hline 2009 & $\begin{array}{l}\text { Sumapaz - } \\
\text { Chingaza }\end{array}$ & $\begin{array}{l}\text { Primer reporte de la afectación de los frailejones describiendo sintomas de } \\
\text { encrespamiento. }\end{array}$ \\
\hline 2010 & $\begin{array}{l}\text { Sumapaz - } \\
\text { Chingaza }\end{array}$ & $\begin{array}{l}\text { Reportes de afectaciones relacionadas con hongos patógenos del género } \\
\text { Colletotrichum e insectos del género Dyscolus }\end{array}$ \\
\hline \multicolumn{3}{|l|}{2011} \\
\hline 2012 & $\begin{array}{l}\text { Sumapaz - } \\
\text { Chingaza }\end{array}$ & $\begin{array}{l}\text { Registro de } 22 \text { géneros de posibles hongos fitopatógenos presentes en hojas de } \\
\text { frailejones sanos y enfermos de la especie E. grandiflora, entre los que se destacan } \\
\text { Fusarium, Botrytis y Alternaria. }\end{array}$ \\
\hline \multirow{3}{*}{2013} & \multirow{3}{*}{$\begin{array}{l}\text { Sumapaz - } \\
\text { Chingaza }\end{array}$} & $\begin{array}{l}\text { Se reportan hongos de los géneros Fusarium, Peciomyces, Alternaria, Cladosporium y } \\
\text { Mucor asociados a frailejones E. grandiflora sanos y enfermos }\end{array}$ \\
\hline & & Reporte en E. argentea de mayor incidencia de la afectación en épocas secas. \\
\hline & & $\begin{array}{l}\text { Asociación de la larva Hellinsia sp. a pérdida de tejidos, clorosis y deformación de las } \\
\text { hojas de los frailejones Espeletia } s p \text {. }\end{array}$ \\
\hline \multirow[b]{2}{*}{2014} & \multirow{2}{*}{$\begin{array}{l}\text { Sumapaz - } \\
\text { Chingaza }\end{array}$} & $\begin{array}{l}\text { Hongos de los géneros Cladosporium, Mucor y Alternaria estan asociados a frailejones } \\
\text { E. argentea enfermos. }\end{array}$ \\
\hline & & $\begin{array}{l}\text { Hongos de los géneros Penicillium, Aspergillus, Paecilomyces, Cladosporium y } \\
\text { Bauveria se encuentran asociados a frailejones E. grandiflora sanos y enfermos. }\end{array}$ \\
\hline \multirow[b]{2}{*}{2015} & \multirow{2}{*}{$\begin{array}{l}\text { Sumapaz - } \\
\text { Chingaza }\end{array}$} & $\begin{array}{l}\text { Se reporta hongos de los géneros Fusarium, Penicillum, Paecilomyces, Cladosporium, } \\
\text { Mucor y Lecanicillum en frailejones E. argentea afectados y no afectados }\end{array}$ \\
\hline & & $\begin{array}{l}\text { Se asocia a hongos patógenos del género Botrytis con el sintoma de pérdida de } \\
\text { pubescencia foliar en frailejones E. paipana }\end{array}$ \\
\hline 2016 & \multirow[b]{2}{*}{$\begin{array}{l}\text { Nudo de } \\
\text { los Pastos }\end{array}$} & \\
\hline \multirow[b]{2}{*}{2017} & & Primer reporte de afectación de frailejones en Nariño, para la especie E. pycnophylla \\
\hline & $\begin{array}{l}\text { Sumapaz - } \\
\text { Chingaza }\end{array}$ & $\begin{array}{l}\text { Identificación de las especies fúngicas Clonostachys rosea, Botrytis sp., Fusarium } \\
\text { oxysporum, Epiccocum nigrum, Giberella zea y Trichoderma harizanum asociados a } \\
\text { lesiones de hojas en Espeletia sp. }\end{array}$ \\
\hline 2018 & $\begin{array}{l}\text { Sumapaz - } \\
\text { Chingaza }\end{array}$ & $\begin{array}{l}\text { Hongos de los géneros Fusarium, Epiccocum y Curvularia asociados a la } \\
\text { sintomatologia de frailejones Espeletia sp. }\end{array}$ \\
\hline \multirow{8}{*}{2019} & \multirow{6}{*}{$\begin{array}{l}\text { Nudo de } \\
\text { los Pastos }\end{array}$} & $\begin{array}{l}\text { Hongos de los géneros Nigrospora, Claviceps, Aspergillus, Pestalotiopsis e Hipoxylon } \\
\text { relacionados con necrosis, clorosis y entorchamiento en frailejones E. pycnophylla }\end{array}$ \\
\hline & & Segundo reporte de afectación de frailejones E. pycnophylla en Nariño \\
\hline & & Tercer reporte de afectación de frailenones E. pycnophylla en Nariño \\
\hline & & $\begin{array}{l}\text { Hongos de los géneros Fusarium, Sclerotinia, Colletotrichum y Phoma asociados a la } \\
\text { enfermedad de los frailejones E. pycnophylla }\end{array}$ \\
\hline & & $\begin{array}{l}\text { Géneros de insectos Neomyopites, Dyscolus, Diabrótica, Bradysia y Carphophilus como } \\
\text { posibles vectores de hongos fitopatógenos en frailejones E. pycnophylla }\end{array}$ \\
\hline & & $\begin{array}{l}\text { Hongos de los géneros Fusarium, Botrytis, Alternaria y el Crhomista Pythium asociados } \\
\text { a la rizósfera, igualmente especies endófitas, saprófitos y posibles patogenos } \\
\text { destacando a F. oxysporum, F. graminearum, Botrytis cinerea, Epicoccum nirum, } \\
\text { Phoma sp de frailejones E. pycnophylla enfermos }\end{array}$ \\
\hline & $\begin{array}{l}\text { Cordillera } \\
\text { de Mérida }\end{array}$ & $\begin{array}{l}\text { Reporte de problemas fitosanitarios en rosetas gigantes Coespeletia spicata y } \\
\text { Coespeletia timotensis }\end{array}$ \\
\hline & $\begin{array}{l}\text { Sumapaz - } \\
\text { Chingaza }\end{array}$ & $\begin{array}{l}\text { La especie Sclerotinia sclerotium se identificó como agente causal de la enfermedad } \\
\text { donomida pudrición blanca en E. grandiflora }\end{array}$ \\
\hline
\end{tabular}

Figura 2. Línea de tiempo de reportes de aparición de síntomas en páramos de Colombia y Venezuela. 


\section{Metodología}

\section{Colección de información asociada con el declive y muerte de frailejones}

Los documentos se colectaron de manera automática usando las cadenas de búsqueda ("muerte” AND “frailejón”) como cadena de búsqueda en Google Scholar obteniendo 87 documentos. Estos documentos fueron guardados directamente de Google Scholar al paquete informático de gestión de referencias F1000 Workspace. Esta plataforma facilita el manejo de estos documentos considerando que una gran parte de ellos son reportes institucionales y tesis de grado carentes de metadatos disponibles (literatura gris) y deben ser procesados manualmente. Cadenas de búsqueda específica fueron desarrolladas para complementar la información sobre las relaciones. Los autores cumplieron la función de expertos para proveer información adicional disciplinar.

\section{Construcción del modelo conceptual que describe el declive y muerte de los frailejones en los Andes del Norte}

Este modelo fue construido usando un protocolo iterativo que incluye análisis estructural del sistema a representar (definición de los límites del modelo y elementos) y el análisis funcional de los procesos entre los elementos identificados (Lamanda et al., 2012). Los componentes del modelo se dividieron en tres categorías: factores ambientales (clima y suelo), unidades de páramo distribuidas en los Andes del Norte, y variables indicadoras del estado sanitario de estas unidades o mortalidad (Lamanda et al., 2012) (Figura 2). Los componentes y las relaciones entre ellos fueron estimados a partir de la información bibliográfica disponible usando cadenas de búsquedas específicas para encontrar información detallada de las relaciones. El análisis funcional describe los efectos generales del clima y el suelo sobre la población de frailejones y las interacciones de estas poblaciones con otros agentes biológicos considerados responsables del declive y muerte de estas plantas.

El propósito de este modelo conceptual es describir a escala de plantas individuales una representación funcional de las interacciones biológicas que conducen al declive y la muerte de frailejones en los Andes del Norte usando las hipótesis y evidencia de campo resultante del trabajo de varios grupos de investigación principalmente en Colombia (Tabla 1). La representación está fundamentada en un enfoque de sistemas y fue complementada con teorías generales sobre el funcionamiento de ecosistemas. Las relaciones entre los componentes del sistema describen la interacción de los agentes biológicos considerados responsables de la muerte de frailejones en los ecosistemas de páramos. Para las poblaciones de frailejones, siguiendo el modelo espiral de declive (Bulaon \& MacKenzie, 2007), el cambio climático es considerado un factor activador de la mortalidad, el suelo un factor de predisposición y la interacción con otros agentes biológicos son considerados factores contribuyentes a la mortalidad observada (Figura 2).

\section{Resultados}

\section{Cambio climático global como factor de predisposición al declive y muerte de los frailejones}

Efecto del cambio climático sobre los ecosistemas tropicales alpinos. El cambio climático global provocará un incremento en los ecosistemas tropicales alpinos de hasta $4.5^{\circ} \mathrm{C}$ (Bradley et al., 2006; Anthelme et al., 2015). En los Andes este cambio en las temperaturas resulta en disminución de la nubosidad y precipitación que generará contracción de los ecosistemas de bosque nublado y páramo (Helmer et al., 2019). El movimiento ascendente de zonas de vida causará la fragmentación y reducción del nicho de las poblaciones vegetales lo que dificultará las labores de conservación. En asocio con el incremento de la intervención antrópica, los ecosistemas alpinos tropicales sufrirán un proceso intenso de insularidad que probablemente resulte en extinción de especies o 
incremento en el endemismo (Anthelme et al., 2014). La dinámica de la sucesión primaria en las comunidades tropicales alpinas es lenta en comparación con la velocidad de cambio climático lo que genera un rezago en la adaptación de estas comunidades vegetales alpinas y probablemente la extinción de especies (Zimmer et al., 2017).

En el caso de los ecosistemas alpinos tropicales, la evidencia apunta a que los bosques tropicales de niebla no tienen la capacidad de invadir los ecosistemas ubicados sobre la línea de árboles si la temperatura llegara a aumentar. Este efecto es conocido como techo de praderas, y en este documento lo denominaremos el techo de páramos. La línea de árboles tropical alpina (a diferencia de su contraparte temperada) no esta únicamente definida por la temperatura sino por otros factores adicionales. Las variaciones extremas de temperatura reducen la supervivencia y crecimiento de árboles jóvenes en las praderas abiertas. Estos individuos también son afectados por el estrés hídrico estacional, los altos niveles de radiación solar, la competición con las gramíneas y la baja dispersión de semillas en las praderas que reducen o limitan el establecimiento de plántulas de árboles más allá de la cobertura del bosque. Las actividades antrópicas de pastoreo y quemas también afectan el establecimiento de los árboles en los pastizales de páramo (Bader et al., 2007, 2008; Rehm \& Feeley, 2015)

Efecto del cambio climático sobre los cinturones de frailejones. Considerando el efecto de techo de páramo, el cambio climático va a provocar ampliación del subpáramo (o cinturón de ericáceas) y ascenso del cinturón de frailejones (o páramo de pastizales) y del superpáramo. En las siguientes décadas presenciaremos transición del páramo dominado por espeletias a un páramo con un paisaje predominante de arbustos enanos y praderas. Simulaciones del efecto del incremento de la temperatura sobre la distribución de especies de Espeletia muestra que este género perderá representatividad en el páramo tanto en área como en número de especies. En algunos escenarios, es esperada la extinción de estas especies en las siguientes dos décadas y la predominancia de pastizales con individuos aislados provenientes del subpáramo (Chala et al., 2016; Mavárez et al., 2018).

Efecto del cambio climático sobre insectos plagas, patógenos y plantas invasivas. El cambio climático no solo generará el desplazamiento de bosques y comunidades vegetales alpinas sino que provocará efectos adicionales con el desplazamiento de insectos plaga, patógenos y plantas invasivas (Dukes et al., 2009; Smith-McKenna et al., 2014). Estas especies si son plagas de los frailejones acelerarán la transformación de los páramos en pastizales. Estos cambios en las interacciones de los frailejones han ocurrido en cuestión de décadas. La densidad y diversidad de insectos consumiendo hojas de frailejones era baja en los años 1980s mientras que actualmente se observa consumo intenso por lepidópteros y mayor presencia de daño por hongos (Llambí et al., 2019a). El incremento de la temperatura también atraerá a los humanos, que encontrarán nuevas tierras para su ganado intensificando los procesos de quema de las áreas alpinas tropicales (Buytaert et al., 2011; Kidane et al., 2019).

Existe la posibilidad de que los frailejones puedan adaptarse a los cambios en su actual nicho o que las emisiones de gases disminuyan retrasando o evitando el efecto esperado del cambio climático, permitiendo que las poblaciones de frailejones puedan sobrevivir. Las probabilidades de ocurrencia de este escenario solo pueden maximizarse si aseguramos que las poblaciones de Espeletia puedan mantener su mayor número posible por más tiempo. 


\section{Factores bióticos contribuyentes al declive y muerte de los frailejones}

Como resultado de la revisión de los documentos que describen agentes biológicos asociados al declive de las poblaciones de frailejones las siguientes hipótesis de interacciones biológicas (interacciones entres componentes del sistema, $\mathrm{HC}$ ) conducentes a la muerte de las plantas han sido planteadas:

- HC1: Pérdida de la función de la raíz como resultado de patógenos radiculares (Tabla 2) o del consumo por Entimidos (Tabla 3)

- HC2: Ataque a los tallos por picudos de la subfamilia Baridinae o por escolítidos (este último incluye el posterior crecimiento de hongos Ambrosia en las plantas) (Tabla 4)

- HC3: Pérdida de área foliar ocasionado por patógenos foliares (Tabla 2) y herbivoría de insectos (Tabla 5)

\section{Plagas e insectos asociados al daño de plantas de frailejón}

\section{HC1: Pérdida de la función de la raíz como resultado del consumo por insectos de la subfamilia} Entiminae

La presencia de individuos de la subfamilia Entiminae se registra en el Parque Nacional Natural Cocuy en donde se observó alimentación y reproducción en la roseta de Espeletia lopezzi (Camacho \& Marroquin, 2015) (Tabla 2), Individuos de esta subfamilia también fueron colectados en la roseta de Espeletia pycnophylla con cierto grado de entorchamiento y clorosis en el Páramo de Paja Blanca (Nariño) (Galindez, 2019). Adicionalmente, Hadromeropsis annae (Entiminae) ha sido reportado asociado a hojas y hojarasca de frailejones en el páramo de Sumapaz (Anderson, 2008).

Descripción de la hipótesis propuesta. La subfamilia Entiminae es uno de los grupos más diversos de Curculionidae (Chow et al., 2008) (Muñoz-Tobar \& Caterino, 2019). Son plagas en Colombia en cultivos de cítricos por consumo de raíces y hojas (Gallego et al., 2012). Siguiendo el hábito de los Entiminae reportado para otras plantas (Grafton-Cradwell et al., 2004; Instituto Colombiano Agropecuario, 2012; Mehrnejad et al., 2017; Gosik et al., 2017), el siguiente escenario es propuesto:

- Los adultos consumen meristemos y hojas y depositan los huevos en las bases de las rosetas, las larvas emergen de los huevos que caen al suelo donde pueden alimentarse de la biomasa en descomposición o de las raíces de los frailejones. Las larvas jóvenes se mueven por la superficie antes de excavar en el suelo para encontrar raíces de las que se alimentan, de manera que inicialmente se alimentan de raíces más pequeñas y a medida que las larvas maduran logran desplazarse hacia raíces más grandes

- El consumo de las raíces de los frailejones por estos insectos provocaría deficiencia nutricional y estrés hídrico que resulta en los síntomas de marchitamiento observado. El daño en hojas es el resultado del consumo por los adultos que emergieron de los túneles en el suelo. Las entradas en la raíz facilitan la colonización por patógenos lo que acelera el proceso de pudrición radicular.

El desarrollo de las larvas de entiminae en las plantas de frailejón provocaría la formación de agallas o proliferación de raíces laterales para subsanar el consumo del insecto considerando la información reportada para curculionidos consumidores de raíces (Skuhrovec et al., 2019). Sin embargo hasta el momento no existen reportes de observación de agallas o proliferación de raíces en las plantas de frailejón y en consecuencia no existe evidencia para afirmar que los entiminos están infectando las raíces. 


\section{HC2: Ataque a los tallos por picudos de la subfamilia Baridinae o por una simbiosis Ambrosia (escolítidos y hongos ambrosia asociados)}

La presencia de individuos de la subfamilia Baridinae se relaciona con el daño observado en Espeletia lopezii del parque Nacional Natural Páramo del Cocuy, de acuerdo con las observaciones de los autores este insecto completa su desarrollo en el sistema vascular de los frailejones generando serias lesiones (Camacho \& Marroquin, 2015). Este insecto es conocido como escarabajo de ambrosia. Otros curculiónidos se registran en Espeletia argentea y Espeletia grandiflora en el páramo de Cruz Verde y en la artropofauna epígea del páramo de Estambul en Tolima (Reinoso-Flórez et al., 2016).

Descripción de la hipótesis propuesta. Los Baridinae son escarabajos que se alimentan como larvas e imagos en las partes verdes de la planta. Las larvas son frecuentemente perforadoras de tallos. Los Baridinae no son escarabajos ambrosia pero existe evidencia que son capaces de "robar" y ocupar los túneles con granjas que los escarabajos ambrosia han creado. Sin embargo no existe evidencia de que sean transmisores efectivos de los hongos ambrosia (Kirkendall et al., 2015; Reed et al., 2015).

La simbiosis ambrosia describe una interacción mutualista entre escarabajos perforadores de tallos de las subfamilias Scolytinae y Platypodinae (los escarabajos ambrosia) y varias especies de hongos de las familias Ophiostomatales, Microascales, Hypocreales y Saccharomycotina. Los socios de esta simbiosis tienen funciones complementarias: el insecto hace las veces de vector mecánico excavando túneles dentro del tallo de la planta y transportando el hongo, mientras el hongo crece dentro de las túneles, extrayendo nutrientes y proveyendo micelio que es consumido por el insecto (Kostovcik et al., 2015; Hulcr \& Stelinski, 2017; Vanderpool et al., 2018).

El siguiente escenario es propuesto para explicar cómo el daño al tallo puede provocar la muerte de los frailejones:

- Los frailejones son hospederos regulares de insectos pertenecientes a la familia Baridinae, construyendo túneles en competencia con otros escarabajos.

- Las plantas de frailejón estresadas son atacadas en mayor frecuencia e intensidad por escolítidos (y platipodos) hasta provocar su muerte. Evidencia previa ha demostrado que plantas estresadas producen etanol que es usado por los escarabajos ambrosia para identificar los hospederos vegetales más apropiados (Kimmerer \& Kozlowski, 1982; Ranger et al., 2010, 2012). Los individuos más estresados son atacados y producen más etanol como resultado del estrés asociado al ataque que termina atrayendo mas y mas coleópteros.

- La colonización de una planta viva por un escarabajo ambrosia es un proceso de escaso éxito pero los ataques sucesivos incrementan la probabilidad de que los hongos ambrosía puedan infectar de manera efectiva a la planta. Una vez la planta ha sido infectada, este inicia su crecimiento produciendo más etanol, que termina atrayendo más coleópteros ambrosia (Hulcr \& Stelinski, 2017; Ploetz et al., 2017; Ranger et al., 2018). Si existe una simbiosis ambrosia atacando los frailejones, la agresividad del hongo ambrosia incrementa la probabilidad de que los frailejones sean colonizados.

En el momento no existe una estimación de la relación entre la perforación del tallo y la muerte de las plantas de frailejones, ni de la presencia de hongos ambrosia. Sin embargo en los últimos años, los hongos ambrosia han estado involucrados en el declive de bosques naturales y cultivados, y especialmente atacando plantas que ya se encuentran estresadas. 


\section{HC3: Pérdida de área foliar ocasionada por herbivoría de lepidópteros}

En 2009 fue registrada por primera vez en el PNN Sumapaz el consumo de meristemos de E. grandiflora por larvas del lepidóptero Oidaematophorus espeletiae (Medina et al., 2010; Hernández et al., 2014; Muñoz-Rodríguez, 2015; Beltrán Morales, 2018). En 2013 se reportó la presencia de larvas del género Hellinsia sp. (Pterophoridae) formando galerías en las hojas de Espeletia sp que conducen a una deformación severa de las hojas (entorchamiento) que ocasiona la pérdida de tejido foliar (Salinas et al., 2013).

\section{Background e Hipótesis propuestas}

La familia Pterophoridae (Lepidoptera) contiene alrededor de 1136 especies distribuidas a nivel mundial (Vargas \& Parra, 2005), en su mayoría las plantas hospederas de la familia Asteraceae (Kitching \& Rawlins, 1998). El daño por consumo de tejidos vivos ocurre durante la etapa de larva en la que minan las hojas de la planta. El siguiente escenario es propuesto:

- Los adultos ovipositan en las superficies de las hojas de Espeletia sp. Una vez los huevos eclosionan, las larvas consumen la hoja donde nacieron hasta completar su desarrollo y solo la abandonan como adultos para buscar nuevas hojas para ovipositar.

- El consumo masivo de tejido foliar desencadena un conjunto complejo de respuestas moleculares y fisiológicas en las plantas que tienen efectos negativos directos sobre el crecimiento de hojas, morfología y reproducción debido en gran medida a la reducción del área fotosintética y del área de actividades de la planta como la dinámica hidráulica y el intercambio de gases (Zhou et al., 2015). Debido a la presencia de larvas de insectos dentro de las hojas, estas se vuelven asimétricas, aparecen agujeros o faltan partes que han sido extraídas (Aldea et al., 2005). Una distribución desproporcionada de nutrientes entre las áreas dañadas y normales de una hoja puede provocar asimetría de la hoja.

- El consumo de la venación de la hoja altera la conductancia hidráulica y en ausencia de vías alternas para el transporte de agua, las consecuencias del daño a la venación pueden conducir a la desecación de la hoja (Sack \& Holbrook, 2006; Nabity et al., 2009).

- El consumo de hojas del meristemo no solo afecta la renovación del área fotosintética, también la posibilidad de generación de órganos reproductivos, poniendo en riesgo la permanencia de la especie en el área donde se presenta la afectación (Liu et al., 2015).

- Además de afectar directamente el tejido fotosintético, los herbívoros pueden afectar indirectamente el intercambio de gases en el tejido restante al desviar recursos para la producción de compuestos de defensa que implican un alto costo energético o interrumpir el transporte de nutrientes y agua (Aldea et al., 2005);(Nykänen \& Koricheva, 2004).

Hasta el momento, no existe una estimación del efecto del daño provocado por herbivoría de lepidópteros en el declive de las poblaciones de Espeletia. La obtención de datos de ciclo de vida y dinámica temporal de las poblaciones de las especies de lepidópteros reportadas facilitará el desarrollo de simulaciones del daño de estas pestes y su efecto futuro sobre las poblaciones de frailejones.

Otros insectos. Insectos coleoptera han sido reportados asociados a daño en rosetas (Camacho Blanco \& Marroquin Ramirez, 2014). Los reportes de herbivoría en Espeletia datan de las observaciones de Sturm (1990) en el Páramo de Cumbal (Nariño), en donde identifica que miembros de la familia Curculionidae pueden llegar a consumir hasta el $10 \%$ de la lámina foliar de E. pycnophylla. También se ha reportado la presencia de carábidos, pero estos son escarabajos depredadores comunes en las comunidades de los páramos (Morret, 2005). La evidencia 
recolectada no muestra que el consumo foliar por escarabajos pueda llegar a tener repercusiones en la mortalidad de las plantas de frailejón.

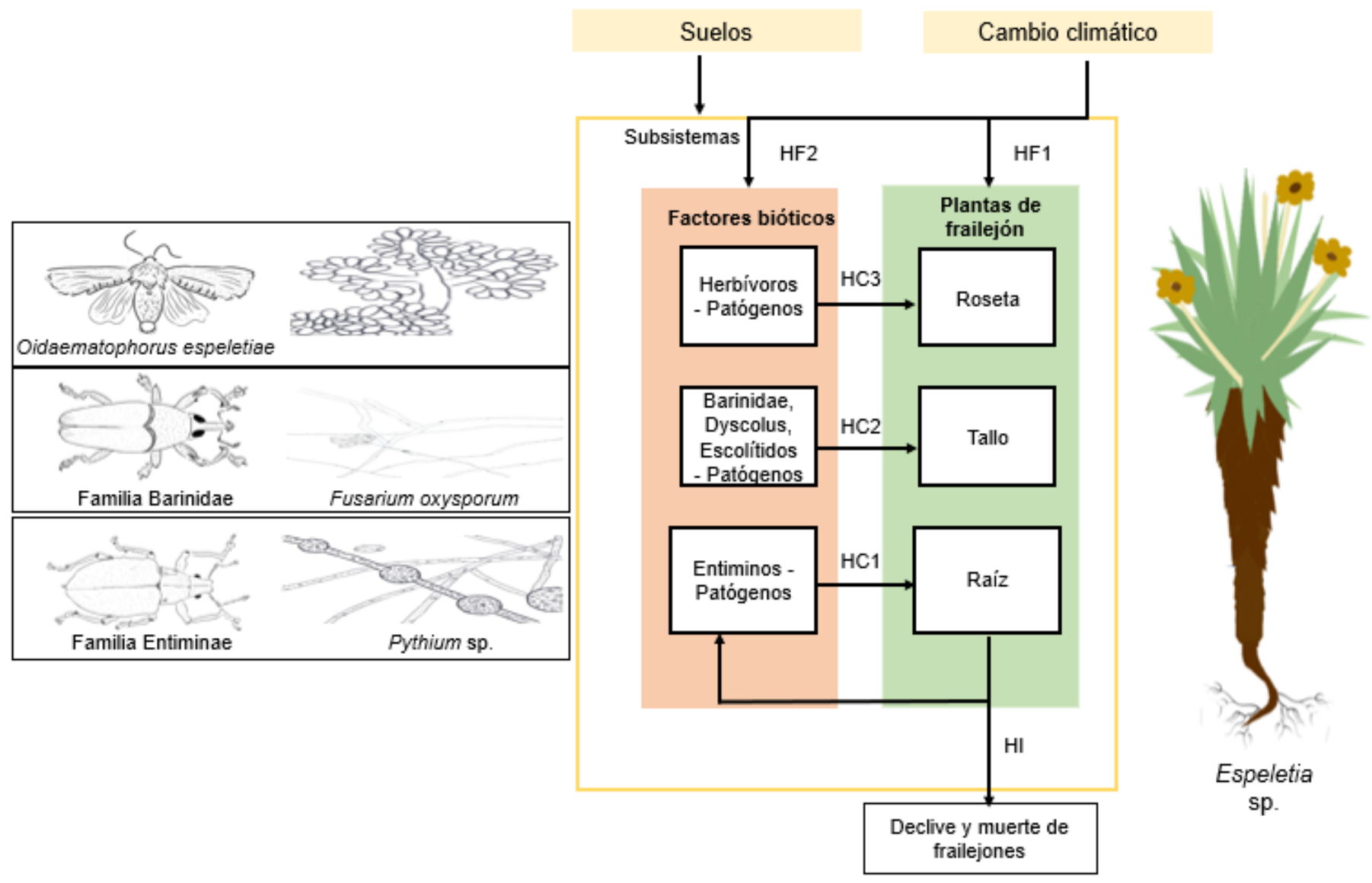

Figura 3. Modelo conceptual describiendo a escala de plantas individuales una representación funcional del declive y muerte de frailejones en los Andes del Norte. Tres hipótesis que explican las interacciones entre plantas de frailejón y agentes biológicos: HC1: Pérdida de la función de la raíz como resultado del consumo por Entimidos o patógenos radiculares; HC2: Ataque a los tallos por picudos de la subfamilia Baridinae o por escolítidos (este último incluye el posterior crecimiento de hongos Ambrosia en las plantas); y, HC3: Pérdida de área foliar ocasionada por herbivoría de insectos y patógenos foliares. HC describe interacciones entre componentes del sistema. HF describe las interacciones entre los factores ambientales y los componentes del sistema. HI describe las interacciones de los componentes del sistema con el indicador de desempeño del sistema. 


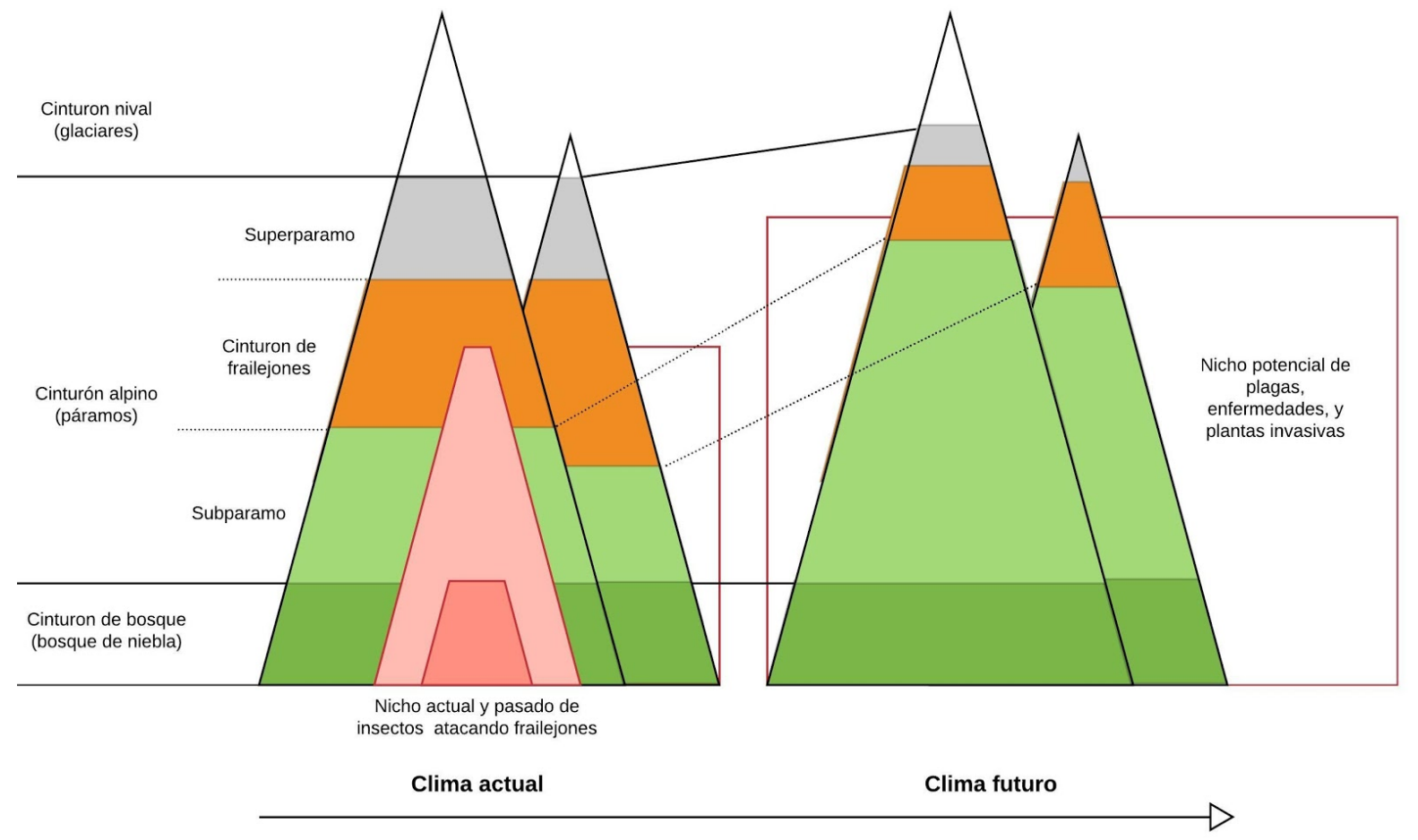

Figura 4. Representación esquemática del efecto del cambio climático sobre el cinturón alpino tropical. En consideración de la hipótesis de "techo de páramo", la línea de árboles permanece estática aun a pesar del aumento de la temperatura. Los ecotonos alpinos tropicales (Andes/Afro Alpinos) sufren desplazamiento ascendente como resultado del incremento de la temperatura: (1) Ecotono inferior (subpáramo / cinturón de ericáceas), (2) Ecotono intermedio o cinturón de rosetas gigantes (Frailejones / Lobelias y Senecios), y (3) Ecotono superior (Superpáramo). La ocurrencia del techo de páramo provoca la ampliación del ecotono inferior alpino: subpáramos en los Andes. En tonos de rojo se muestra el nicho ocupado por pestes y patógenos que atacan los frailejones. El tono más intenso muestra el nicho que ocuparon en el pasado confinados al cinturón de bosque. El tono más claro muestra el nicho actual donde el aumento de la temperatura ha permitido su ascenso altitudinal. Las cajas delineadas en rojo muestran los nichos potenciales actuales y futuros de estas plagas de los frailejones. Las líneas que definen cada uno de los cinturones no son constantes y varían en altura. Así por ejemplo es posible encontrar poblaciones de frailejones a altitudes por debajo de las esperadas (páramos azonales en la montaña de fondo). Estos páramos están más expuestos al ataque por las poblaciones de plagas en ascenso. 


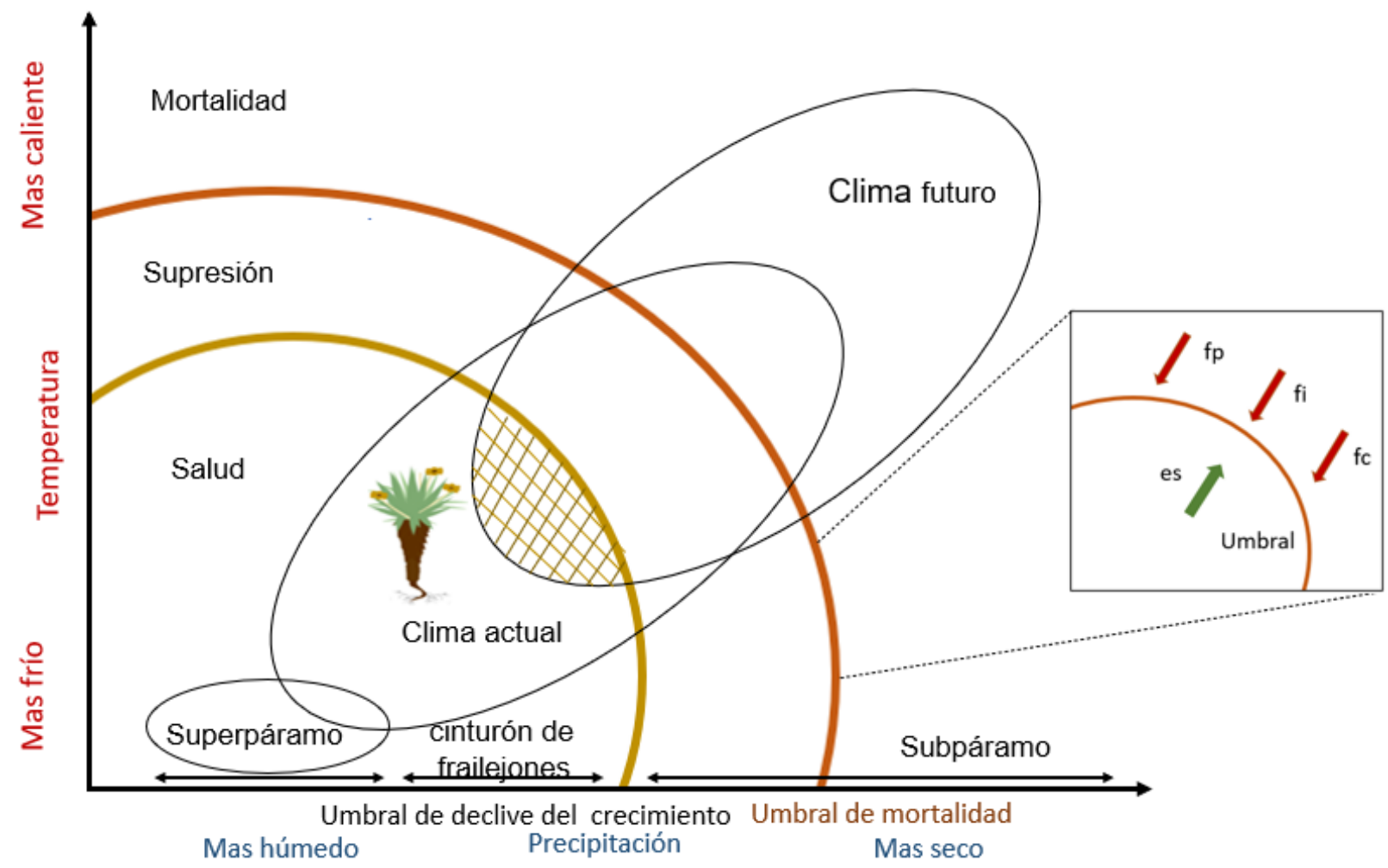

Figura 5. Diagrama conceptual de los cambios en precipitación y temperatura del clima actual y futuro del cinturón alpino tropical. El área del cinturón no será afectada considerando la hipótesis del "Techo de páramos", pero el nicho de los frailejones sufrirá drásticas reducciones. Alternativamente en azul se muestra el efecto de la duración y la intensidad de la sequía sobre estas poblaciones. Los rangos de temperatura, precipitación y sequía que definen el límite específico de mortalidad para las especies de frailejones deben ser determinados a través de experimentos o modelos. Extendiendo el modelo espiral de declive (Manion, 1991) a las poblaciones de frailejones, proponemos que el cambio climático es considerado un factor instigante (fi) de la mortalidad de los frailejones, el suelo un factor de predisposición (fp) y la interacción con otros agentes biológicos son considerados factores contribuyentes (fc) a la mortalidad observada. Estos factores en conjunto crean las condiciones para que el umbral de mortalidad ocurra antes de que las condiciones climáticas esperadas se cumplan. Ningún factor que permita disminuir la mortalidad (factor estabilizante (es) fue identificado en el desarrollo de este modelo conceptual. Si los problemas sanitarios actuales provocan una pérdida neta en la población de frailejones, el umbral de supresión se convertirá en el umbral de mortalidad, y los frailejones pueden extinguirse sin haber alcanzado sus nichos altitudinales futuros. El diagrama presentado es una adaptación a las poblaciones de frailejones de modelos conceptuales previamente descritos para otras poblaciones de plantas (Allen et al., 2010, 2015; Wang et al., 2012; Breshears et al., 2016) 
Tabla 1. Descripción de elementos del sistema que describe el proceso de declive y muerte de frailejones. Las escalas espaciales y temporales de estos elementos son incluidas.

\begin{tabular}{|c|c|c|c|}
\hline $\begin{array}{l}\text { Elementos del } \\
\text { Sistema }\end{array}$ & Interacción con las poblaciones de frailejones / Descripción & $\begin{array}{l}\text { Escala } \\
\text { espacial }\end{array}$ & $\begin{array}{l}\text { Escala } \\
\text { temporal }\end{array}$ \\
\hline \multicolumn{4}{|l|}{ Factores (1) } \\
\hline $\begin{array}{l}\text { Cambio } \\
\text { climático } \\
\text { global }\end{array}$ & $\begin{array}{l}\text { Este es un factor de predisposición en el proceso de declive y muerte de los frailejones. Es } \\
\text { esperado un incremento de la temperatura global de hasta } 4^{\circ} \mathrm{C} \text { (Raftery et al., 2017), lo que } \\
\text { provocaría en ecosistemas alpinos tropicales un desplazamiento ascendente del cinturón de } \\
\text { frailejones (Hofstede et al., 2014). El clima también actúa como factor de predisposición para el } \\
\text { ascenso de nicho de poblaciones de insectos e incremento de la tasa de crecimiento de patógenos } \\
\text { posiblemente endófitos u oportunistas. }\end{array}$ & $\begin{array}{l}\text { Global } \\
\text { (2) }\end{array}$ & $\begin{array}{l}\text { Largo } \\
\text { plazo }\end{array}$ \\
\hline $\begin{array}{l}\text { Suelo } \\
\text { Microclimas }\end{array}$ & $\begin{array}{l}\text { Factores incitantes del declive de las poblaciones de frailejones. Areas del paisaje de páramo son } \\
\text { más propensas a estrés fisiológico asociado a variaciones de suelo y patrones regionales de } \\
\text { precipitación (Anderson et al., 2012)). }\end{array}$ & $\begin{array}{l}\text { Regiones } \\
\text { Paisajes }\end{array}$ & $\begin{array}{l}\text { Largo } \\
\text { plazo }\end{array}$ \\
\hline $\begin{array}{l}\text { Intervención } \\
\text { antrópica local }\end{array}$ & $\begin{array}{l}\text { La intervención antrópica es un factor que contribuye a la desaparición de los frailejones, pero no } \\
\text { está relacionada de manera directa en la línea de causalidad del declive y mortalidad de estas } \\
\text { plantas por factores biológicos reportada en este modelo. }\end{array}$ & $\begin{array}{l}\text { Paisaje } \\
\text { Local }\end{array}$ & $\begin{array}{l}\text { Años o } \\
\text { décadas }\end{array}$ \\
\hline
\end{tabular}

\section{Subsistemas}
Factores
bióticos
contribuyentes
Poblaciones de Espeletia
Afectaciones en especies de frailejón asociadas a insectos y hongos, ocasionando un decaimiento en las poblaciones de Espeletia (Varela, 2014). El cambio climático provoca el ascenso de poblaciones de insectos y el desarrollo de nuevos patógenos para los frailejones.
Los frailejones son especies clave en la dinámica del páramo, principalmente debido a su capacidad de captar y regular el agua, haciendo que su permanencia sea imprescindible en el mantenimiento del equilibrio y supervivencia de ecosistemas y comunidades aledañas (Díaz-Granados Ortiz et al., 2005; Ruiz et al., 2008; Rivera-Ospina \& Rodríguez-Murcia, 2011). Estimaciones de nichos futuros predicen extinción para algunas especies de Espeletia en las siguientes décadas (Chala et al., 2016; Mavárez et al., 2018).

$\begin{array}{ll}\text { Paisajes } & \begin{array}{l}\text { Años o } \\ \text { décadas }\end{array} \\ \text { Unidades de } & \\ \text { páramo } & \end{array}$

Nichos de

especies

\section{Indicadores}

Declive
$\begin{aligned} & \text { Clorosis, entorchamiento, necrosis, manchas foliares, pudrición de raíz y haces vasculares (IAvH\& } \\ & \text { PUJ, 2019) }\end{aligned}$
$\begin{aligned} & \text { Debilitamiento y marchitamiento progresivo al final generalizado de plantas en estado juvenil y } \\ & \text { adulto. La muerte en pie ha sido reportada en especies de frailejones de Venezuela (Llambí et al., } \\ & \text { 2019b)y Colombia (Fuentes, 2019; Salazar González et al., 2019). }\end{aligned} \begin{aligned} & \text { Meses, } \\ & \text { Años o } \\ & \text { década }\end{aligned}$
(1) $\begin{aligned} & \text { Los factores de predisposición crea vulnerabilidades para los factores de instigación y estos para los factores de contribución } \\ & \text { que finalmente resulta en mortalidad (Frey et al., 2004). }\end{aligned}$
(2) $\begin{aligned} & \text { Paisajes definidos como unidades de interacción entre los sistemas naturales y sistemas humanos (gobiernos incluidos) } \\ & \text { compuestos por elementos estructurales de cobertura vegetal o uso de la tierra (Walz, 2011). En el caso de las interacciones de } \\ & \text { las plantas de frailejones (hospedero) con los agentes biológicos causantes del declive y muerte, este término engloba los nichos } \\ & \text { de hospederos y parásitos (Johnson et al., 2019). }\end{aligned}$


Tabla 2. Síntomas y microorganismos aislados de frailejones con síntomas de declive o muerte en pie

\begin{tabular}{lll}
\hline Sintomas de enfermedades observados en campo (1) & $\begin{array}{l}\text { Patógenos o microorganismos } \\
\text { aislados (2) }\end{array}$ & $\begin{array}{l}\text { Especies de frailejón } \\
\text { afectadas }\end{array}$ \\
\hline
\end{tabular}

Declive de los frailejones: clorosis, encrespamiento y pudrición de la planta

Encrespamiento, clorosis y pudrición en la base de la roseta Colletotrichum y Fusarium

(Medina et al., 2010)

Encrespamiento, clorosis, manchas, necrosis y pudrición

foliar (González Rocha, 2012))

Clorosis (Prieto, 2017)

Alteraciones en el color de la lámina foliar (Gaitán Naranjo, $\quad$ y Curvularia sp. (2)

2018)

Botrytis cinerea, Phoma sp, Epicoccum

sp, F. graminearum y F. oxysporum

E. grandiflora, E.uribei y E.

argentea

E. argentea

Acremonium, Epicoccum, Nigrospora,

Fusarium graminearum y F. oxysporum

Clonostachys rosea, Botrytis sp. Daldinia

eschscholtzii, Fusarium

oxysporum y Epicoccum nigrum (2)

Fusarium avenaceum, Epicoccum nigrum

E. argéntea

E.grandiflora

E. pycnophylla

Síntomas de encrespamiento, clorosis, necrosis y pudrición

foliar (Florez et al., 2019)

\section{Lesiones foliares}

La presencia de lesiones cloróticas no

E.grandiflora

Lesiones con halo clorótico de los frailejones (Cifuentes

Castellanos, 2017)

aguadas sugiere una infección fúngica.

RNA Virus de doble cadena

E. grandiflora y E. argentea

Mosaico de venas de los frailejones (Cifuentes Castellanos,

2017)
Crecimiento micelial en el envés de las

hojas. Patógeno no identificado

E.grandiflora

Mildeo negro de los frailejones (Cifuentes Castellanos, 2017)

Pudriciones de tallos y raíz

Pudrición blanca (Corredor et al., 2019)

Sclerotinia sclerotium

Pythium sp.

Fusarium sp Phytophthora sp and E.grandiflora

Pudrición de tallo y raíz en plántulas de invernadero Pythium sp

E. grandiflora

E. argentea y E.grandiflora

Pudrición del tallo y raíz (Cifuentes Castellanos, 2017)

(García-Castañeda et al., 2015) 
Pérdida de pubescencia

Pérdida de pubescencia foliar (Buitrago et al., 2015)

$$
\text { Botrytis (2), Fusarium sp E. paipana }
$$

(1) Los síntomas han sido designados en consideración a la terminología comúnmente usada en patología de plantas (Riley et al., 2002; Valverde et al., 2012; Horst, 2013) reemplazando los términos originalmente descritos. Encrespamiento (curling) reemplaza el término entorchamiento usado inicialmente para designar engrosamiento y distorsión de la lámina foliar. Los términos homaposis, homosis y abdosis descritos por (Gaitán Naranjo, 2018) han sido agrupados en alteraciones del color de la lámina foliar. El oscurecimiento de la lámina es un síntoma de necrosis del tejido (blight) probablemente asociado a muerte descendente.

(2) Para estos microorganismos se reporta pruebas de patogenicidad positivas. La prueba de patogenicidad presentada por (Gaitán Naranjo, 2018) muestra crecimiento del patógeno en fragmentos de hojas y no reproducción de los síntomas.

Tabla 3. Descripción de la interacción entre agentes bióticos y plantas de frailejones asociada a la pérdida de la función de la raíz como resultado del consumo de biomasa radicular por Entiminos o patógenos. Interacción entre componentes $\mathrm{HC1}$.

\begin{tabular}{|c|c|c|c|}
\hline $\begin{array}{l}\text { Agente biológico } \\
\text { involucrado }\end{array}$ & Indicadores de declive y muerte de las plantas & $\begin{array}{l}\text { Cómo podrían estar relacionados con el declive } \\
\text { de los frailejones? }\end{array}$ & Localidad \\
\hline \multirow{4}{*}{$\begin{array}{l}\text { Insectos de la } \\
\text { subfamilia } \\
\text { Entiminae (familia } \\
\text { Curculionidae) }\end{array}$} & Adultos de morfoespecies de la subfamilia & \multirow{4}{*}{$\begin{array}{l}\text { Los entiminos son plagas de cultivos agrícolas y en } \\
\text { estado larvario atacan las raíces de las plantas (Gosik \& } \\
\text { Sprick, 2013). } \\
\text { La muerte en pie de los frailejones podría ser explicada } \\
\text { por la pérdida de raíces asociada a entiminos y la } \\
\text { posterior obstrucción en la toma de nutrientes }\end{array}$} & \multirow{3}{*}{$\begin{array}{l}\text { PNN Cocuy } \\
\text { (Colombia) }\end{array}$} \\
\hline & Entiminae fueron reportados asociados a la roseta de & & \\
\hline & frailejones (Camacho \& Marroquin, 2015) & & \\
\hline & $\begin{array}{l}\text { Hadromeropsis annae se identificó asociado a hojas y } \\
\text { hojarasca de Espeletia (Anderson, 2008) }\end{array}$ & & $\begin{array}{l}\text { Páramo de } \\
\text { Sumapaz } \\
\text { (Colombia) }\end{array}$ \\
\hline Hongos y & Géneros como Rhizoctonia y Pythium han sido & \multirow{2}{*}{$\begin{array}{l}\text { Pudrición de punta de raíz y envejecimiento de raíces } \\
\text { jóvenes }\end{array}$} & Pàramo de \\
\hline Oomycetes & $\begin{array}{l}\text { aislados de tejidos radiculares infectados } \\
\text { (García-Castañeda et al., 2015). }\end{array}$ & & Paja Blanca \\
\hline
\end{tabular}


Tabla 4. Descripción de la interacción entre agentes bióticos y plantas de frailejones asociada al ataque a los tallos por picudos de la subfamilia Baridinae, por escolítidos (que incluyen el posterior crecimiento de hongos Ambrosia en las plantas) e insectos carabidae del género Dyscolus. Interacción entre componentes HC2.

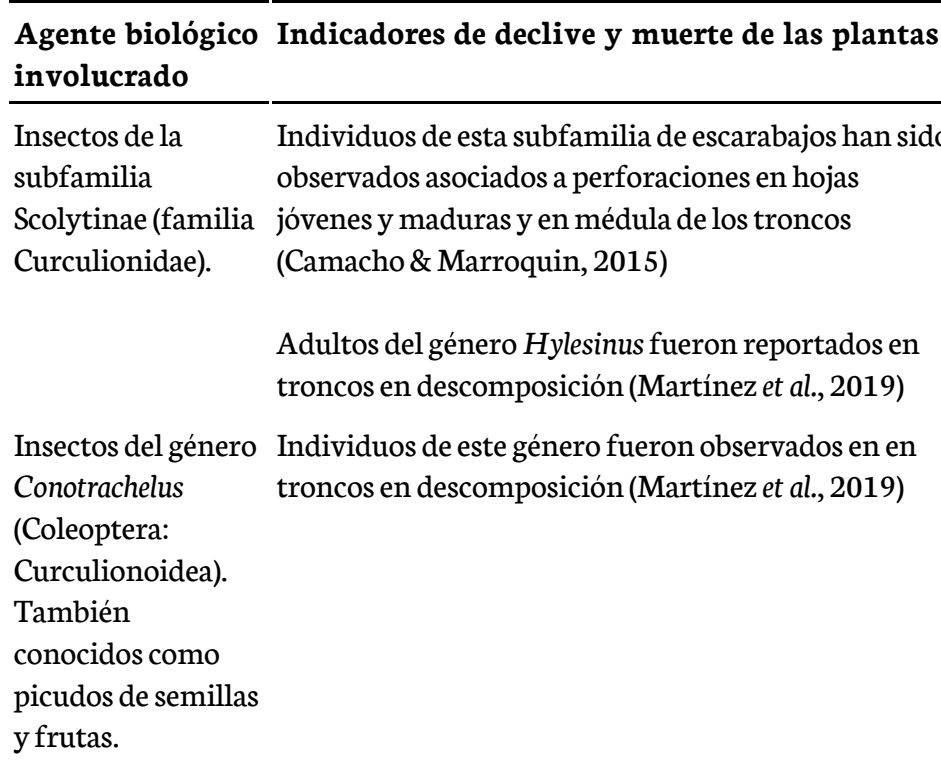

Cómo podrían estar relacionados con el declive Localidad
de los frailejones?
Ce los frailejones?

El daño por escolítidos no es considerado letal. PNN Cocuy Sin embargo, los escolítidos transportan hongos PNN ambrosía que en los últimos años han incrementado su Chingaza patogenicidad hacia sus hospederos vegetales (Ploetz et al., 2013).

Especies de este género Neotropical son plagas de importancia económica de árboles frutales. El rango de hospederos de este insecto incluye las asteráceas. Además del consumo de semillas y frutas son capaces de producir agallas en tallos de varias especies vegetales (Ramamurthy, 2007; Pinzón-Navarro et al., 2010).

El estrés causado por la formación de las agallas puede llegar a ser severo al punto de reducir el potencial hídrico de las hojas y la tasa fotosintética (Raman, 2011).

Hasta el momento no existe evidencia de la presencia de agallas en frailejones causadas por este u otros insectos. Sin embargo, Conotrachelus es usado como controlador biológico de malezas de la familia Asteraceae (McFadyen, 2000; Dhileepan et al., 2018; Maharjan et al., 2019)

Hormigas No asociadas al daño de plantas de frailejón (Martínez et al., 2019)

Estas poblaciones de hormigas se encuentran por encima del rango altitudinal esperado confirmando el efecto del cambio climático sobre la distribución de especies en los Andes.

Carabidae como depredadores consumen otros PNN

Insectos del género Este insecto es un predador reportado en asocio a Dyscolus, galerías en tallos de frailejones (Medina et al., 2010) probablemente (Martínez et al., 2019; Varela, 2019)

Dyscolus escarabajos (Lövei \& Sunderland, 1996). Su presencia en Chingaza las galerías puede estar asociada con el consumo de otros escarabajos ( $u$ otros insectos) responsables de los túneles en el tallo de los frailejones. 
Tabla 5. Descripción de la interacción entre agentes bióticos y plantas de frailejones asociada a la pérdida de área foliar ocasionada por herbivoría de insectos y patógenos foliares. Interacción entre componentes HC3.

\begin{tabular}{|c|c|c|c|}
\hline $\begin{array}{l}\text { Agente biológico } \\
\text { involucrado }\end{array}$ & Indicadores de declive y muerte de las plantas & $\begin{array}{l}\text { Cómo podrían estar relacionados con el declive de los } \\
\text { frailejones? }\end{array}$ & Localidad \\
\hline \multirow[t]{2}{*}{$\begin{array}{l}\text { Oidaematophorus } \\
\text { espeletiae }\end{array}$} & $\begin{array}{l}\text { Consumo de meristemos, pérdida parcial de tejidos y } \\
\text { secamiento de hojas (Salinas et al., 2013; Hernández et } \\
\text { al., 2014; Muñoz, 2015; Fuentes, 2019; Varela, 2019). }\end{array}$ & $\begin{array}{l}\text { El daño foliar no puede explicar la muerte de de las } \\
\text { plantas. Solo afecta entre el 8-25\% de las plantas y el } \\
10 \% \text { del tejido foliar. Sin embargo el consumo de } \\
\text { meristemos es considerable y puede detener el } \\
\text { crecimiento de las plantas. }\end{array}$ & \multirow[t]{2}{*}{$\begin{array}{l}\text { PNN } \\
\text { Chingaza }\end{array}$} \\
\hline & $\begin{array}{l}\text { La presencia de larvas suele asociarse a micosis, y está } \\
\text { a clorosis severa, 'entorchamiento' de las hojas y en } \\
\text { algunas ocasiones a la muerte de los individuos. }\end{array}$ & $\begin{array}{l}\text { Este daño es reportado como asociado a mortalidad, } \\
\text { pero no encontramos evidencia experimental o } \\
\text { asociada que justifique tal afirmación. Tampoco está } \\
\text { verificado que estos insectos pueden actuar como } \\
\text { vectores de hongos. }\end{array}$ & \\
\hline $\begin{array}{l}\text { Hellinsia sp. (familia } \\
\text { Pterophoridae }\end{array}$ & $\begin{array}{l}\text { Este insecto provoca pérdida de tejidos foliares, } \\
\text { clorosis severa y deformación de las hojas (Salinas et } \\
\text { al., 2013) }\end{array}$ & $\begin{array}{l}\text { Los individuos de Espeletia sp. Tienen la capacidad de } \\
\text { continuar con su desarrollo después de ser hospederos } \\
\text { de las larvas de Hellinsia sp. }\end{array}$ & $\begin{array}{l}\text { PNN } \\
\text { Chingaza } \\
\text { (Colombia) }\end{array}$ \\
\hline $\begin{array}{l}\text { Hongos } \\
\text { fitopatógenos (o } \\
\text { endófitos) asociados } \\
\text { a la presencia de } \\
\text { escarabajos y polillas }\end{array}$ & $\begin{array}{l}\text { Varias especies de hongos han sido relacionadas con } \\
\text { clorosis en hojas maduras, deformación de hojas y } \\
\text { pudrición del tallo de individuos vivos (González } \\
\text { Rocha, 2012) } \\
\text { Aislados de los géneros Colletotrichum, Fusarium, } \\
\text { Alternaria y Cladosporium son frecuentemente } \\
\text { obtenidos de tejido foliar (Medina et al., 2010; } \\
\text { González Rocha, 2012; Varela, 2019) }\end{array}$ & $\begin{array}{l}\text { Los hongos pueden infectar los individuos de Espeletia } \\
\text { spp., acelerando su muerte pero hasta el momento no } \\
\text { existe evidencia de patogenicidad de estas cepas } \\
\text { (Postulado de Koch) } \\
\text { Crecimiento del hongo en trozos de hojas de frailejones } \\
\text { ha sido reportado para Fusarium, Curvularia y Epicocum } \\
\text { (Gaitán Naranjo, 2018), pero este reporte no es } \\
\text { evidencia de patogenicidad de estas cepas. }\end{array}$ & $\begin{array}{l}\text { PNN } \\
\text { Chingaza }\end{array}$ \\
\hline Plaga no identificada & $\begin{array}{l}\text { Se reporta herbivoría sin que el insecto responsable } \\
\text { haya sido determinado (Ponce, 2019) }\end{array}$ & & $\begin{array}{l}\text { Páramo El } \\
\text { Ángel } \\
\text { (Ecuador) }\end{array}$ \\
\hline
\end{tabular}

\section{Enfermedades causadas por patógenos en frailejones}

Síntomas de alteraciones del color de la lámina foliar, clorosis y encrespamiento han sido observados en plantas de frailejones (Tabla 2). El encrespamiento es el fenómeno más comúnmente reportado y está asociado a aislamiento de ascomycetes, especialmente de cepas del género Fusarium. Evaluaciones in-leaf de la patogenicidad de $F$. oxysporum muestran que este patógeno es capaz de reproducir los síntomas de encrespamiento observados en campo en E. pycnophylla (Galindez, 2019). Síntomas de encrespamiento están comúnmente asociados a virus, sin embargo existen reportes de ascomicetos capaces de producir esta sintomatología, por ejemplo el encrespamiento de hojas del durazno causado por Taphrina deformans (Moscatello et al., 2017), y el de hojas de algodón causado por Colletotrichum gossypii var. cephalosporioides (Moreno-Moran \& Burbano-Figueroa, 2017). Taphrina deformans puede ocasionar la muerte de los árboles de durazno como resultado del excesivo consumo de azúcares por el patógeno y la pérdida de área fotosintética asociada a la defoliación (Moscatello et al., 2017). Es una de las hipótesis de este estudio que el encrespamiento (junto a la clorosis) son síntomas tempranos de marchitamiento (muerte en pie) e incluye la colonización completa de los órganos de la planta por parte del hongo a partir de infecciones radiculares. En otras especies vegetales afectadas por $F$. oxysporum es común observar esa continuidad de síntomas que terminan en marchitamiento y muerte de la planta (Haglund \& Kraft, 1979; Bani et al., 2012) incluyendo cultivos de asteráceas (Moslemi et al., 2017). 
Además de estos síntomas de declive y marchitamiento de los frailejones, otro grupo de síntomas foliares independientes causados por hongos y virus han sido reportados: manchas foliares, mosaico de las venas y mildeo negro. Los organismos causantes de estas afectaciones no han sido identificados. Las manchas foliares de los frailejones son probablemente ocasionadas por un hongo. El mildeo negro es obviamente causado por un hongo, pero una descripción microscópica del patógeno no ha sido provista. Los síntomas del mosaico de las venas sugiere un origen viral que ha sido confirmado sin identificación del virus (Tabla 2). La incidencia y severidad de estas tres enfermedades es también desconocida. Pudriciones de tallos y raíz ocasionadas por hongos y oomycetes también han sido reportadas. Sin embargo, pruebas de patogenicidad para estos organismos no han sido desarrolladas (Tabla 2).

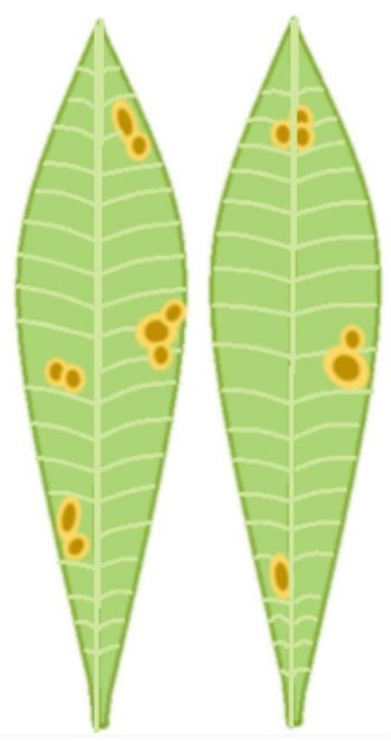

A. Lesiones con halo clorotico

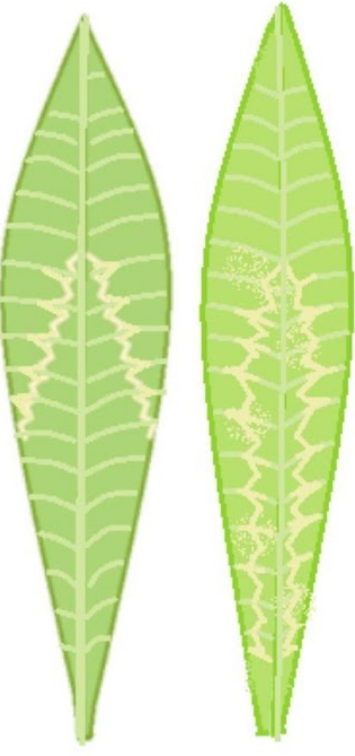

B. Mosaico de las venas
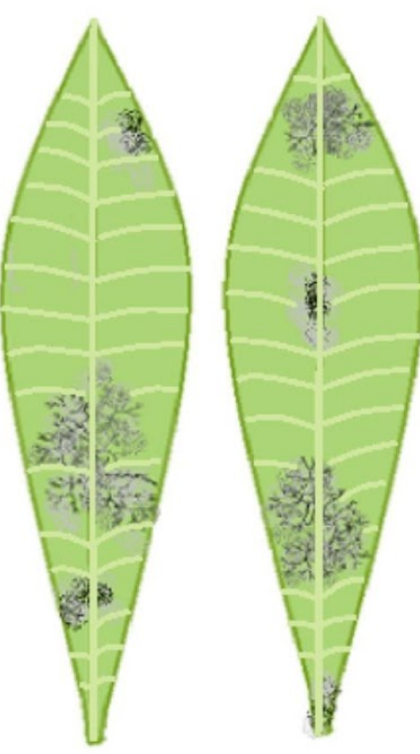

C. Mildeo negro
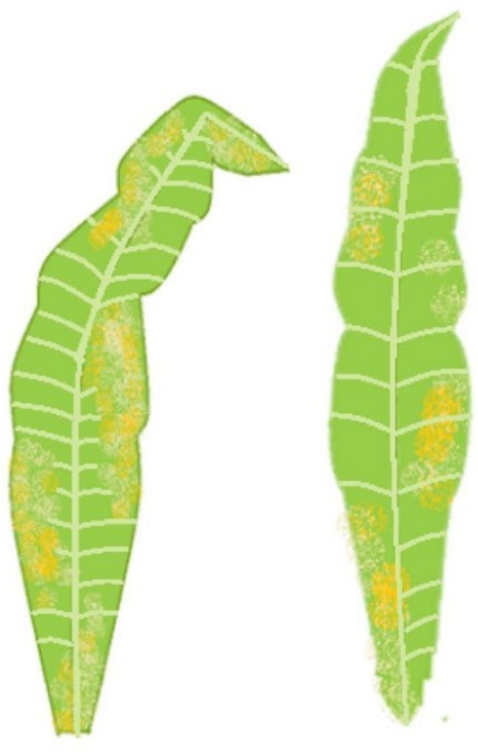

D. Encrespamiento de los frailejones

Figura 6. Representación esquemática de los síntomas de las principales enfermedades observadas en los frailejones. Los agentes etiológicos de estas enfermedades no han sido identificados. A. Son lesiones secas que sugieren un hongo como patógeno. B. El patrón de clorosis sugiere un origen viral que ha sido confirmado sin identificación del organismo. C. La presencia de mildiu sugiere obviamente un origen fúngico. D. El encrespamiento es el síntoma más comúnmente reportado. Un origen múltiple es sugerido para el desarrollo de este síntoma asociado a un fenómeno de marchitamiento y decaimiento de la planta. Reportes y localidades donde estos síntomas han sido observados están descritos en la Tabla 2.

\section{Discussion}

La evidencia colectada localmente y la extrapolable de otros ecosistemas, sugiere que el declive y muerte de los frailejones observado en las últimas décadas es explicado por factores externos, factores de predisposición y factores contribuyentes. El cambio climático es considerado el factor externo responsable del estrés fisiológico de plantas asociado al aumento de la temperatura y sequía. El suelo contribuye de manera regional o local a acentuar el declive y muerte, mientras los factores biológicos contribuyentes de la mortalidad actúan de manera local. El ascenso de las poblaciones de insectos que parasitan las plantas de frailejones también está relacionado con el cambio climático. Las actividades antropogénicas locales contribuyen a la pérdida del páramo en general pero no están relacionadas con la serie de eventos causantes del declive y mortalidad.

Los trabajos de investigación hasta el momento se han concentrado en evaluar el impacto individual de los factores bióticos contribuyentes de la mortalidad de los frailejones. A la fecha no existe evidencia que permita establecer 
con exactitud la responsabilidad de estos factores en el declive de dichas poblaciones. En consideración, con la información proveniente de otros ecosistemas (y la presencia recurrente en los reportes de frailejones afectados), posiblemente los escarabajos de corteza sean el factor contribuyente de mayor valor (Das et al., 2016). Sin embargo, insectos y patógenos asociados a la raíz pueden explicar la muerte en pie observada como factores independientes. Aunque es considerada fundamental la evaluación experimental de cada uno de los factores biológicos a fin de reproducir los síntomas observados en campo y especialmente los efectos de muerte en pie, es aconsejable resolver estas preguntas antes de invertir esfuerzos adicionales en colección de datos:

- Cual es el propósito de un diagnóstico de estas afectaciones en los páramos de la región? Los trabajos de campo y laboratorio pueden adquirir mayor relevancia si están enmarcados dentro de las hipótesis de un modelo a resolver. En el caso de las afectaciones por insectos, por ejemplo es importante en este momento estimar su probabilidad de distribución que combinada con la distribución de las especies de Espeletia permite predecir el nivel de afectación esperado.

- Cual es el enfoque de los estudios para abordar la problemática del declive de los páramos?

- Conocimiento: Cuales son las interacciones que deben priorizarse para entender el declive del páramo?

- Prácticos: Cuáles de estas interacciones son factibles de ser intervenidas para mitigar el declive del páramo?

Estas preguntas y la complejidad del problema descrito se verán enormemente beneficiados con el desarrollo de modelos cuantitativos y simulaciones que permitan estimar el impacto del cambio climático y los factores biológicos sobre el declive y mortalidad de las especies de frailejones. Las simulaciones pueden identificar las variables de mayor valor donde los esfuerzos de investigación e intervención deben ser concentrados. Simulaciones probabilísticas construidas con la participación de actores académicos y sociales (gobiernos y comunidades locales) permiten crear modelos con esfuerzo mínimo, sin la colección adicional de datos, e incluyendo la incertidumbre asociada a factores y componentes del sistema. Estas simulaciones también permiten la evaluación de las intervenciones propuestas y son una guía en el proceso de toma de decisiones y en el desarrollo de políticas públicas nacionales y locales de conservación (Hubbard \& Millar, 2014; Luedeling et al., 2014; Shepherd et al., 2014, 2015). Estas simulaciones también pueden ser usadas en la orientación de experimentos de campo y laboratorio y sus resultados incorporados en el modelo a fin de incrementar su complejidad o reducir la incertidumbre.

Simulaciones describiendo el declive y mortalidad también permitirían estimar si los esfuerzos posibles son suficientes para detener la desaparición de las especies de frailejones o si esta es inevitable. Estas simulaciones también permitirían estimar los cambios esperados para el ecosistema de páramo en el panorama actual de cambio climático. Las estimaciones previas sugieren que más del $80 \%$ de los páramos como hoy los conocemos desaparecerán en 80 años solo por el efecto del cambio climático. La inclusión de plagas y patógenos en estos escenarios acelerará este proceso pero desconocemos la proporción esperada de este impacto.

Es necesario, también analizar la desaparición de los frailejones y la transformación de los páramos desde una perspectiva política y social. Por ejemplo, quién es la institución encargada de orientar políticamente las acciones para la conservación? Esta pregunta no se debe limitar a identificar las instituciones delegadas por los gobiernos nacionales o locales para atender los asuntos de medio ambiente, sino de la necesidad de la construcción de políticas o visiones a largo plazo de objetivos de investigación y desarrollo y colaboración para todas las instituciones dedicadas a la conservación de los páramos en función de una aproximación realista de los recursos financieros disponibles. El establecimiento de una visión a largo plazo entre los actores involucrados será de 
enorme valor para concentrar los esfuerzos en aquellas acciones que permitan obtener los mayores beneficios al tiempo que las iniciativas locales mantienen su independencia y compromiso.

Los ecosistemas tropicales alpinos están distribuidos alrededor del mundo en las Américas, África y Asia (Sklenár et al., 2014). Estos ecosistemas enfrentarán dramáticos cambios en las siguientes décadas que resultaron en la extinción o masiva reducción de nicho de las rosetas gigantes, la especie arquetipo de estos ecosistemas (Kidane et al., 2019). Este documento reporta evidencia de aceleración de este proceso mediada por mayor actividad de patógenos y la migración de insectos favorecida por las crecientes temperaturas. Aunque este documento se concentra en los Andes, no encontramos razones para no pensar que un fenómeno similar enfrentan los ecosistemas alpinos en África del Este y Nueva Guinea, acelerando su transformación en ecosistemas dominado por pastizales y arbustos.

\section{Conclusiones}

El modelo conceptual aquí descrito ofrece un marco de referencia que colecta teorías y trabajos de investigación en la última década usados para explicar el fenómeno de declive y muerte de Espeletias en los Andes del Norte. El modelo además de clasificar funcionalmente los agentes biológicos asociados a este proceso, ofrece una visión a largo plazo de la dinámica de este proceso en función del cambio climático global. El modelo también hace a un llamado al desarrollo de esfuerzos coordinados entre investigadores e instituciones de los países en los Andes del Norte y llama la atención a la desaparición de estos ecosistemas en otros continentes. 


\section{Referencias}

Aldea M, Hamilton JG, Resti JP, Zangerl AR, Berenbaum MR, D eLUCIA EH, 2005. Indirect effects of insect herbivory on leaf gas exchange in soybean. Plant, Cell \& Environment 28, 402-411.

Allen CD, Breshears DD, McDowell NG, 2015. On underestimation of global vulnerability to tree mortality and forest die-off from hotter drought in the Anthropocene. Ecosphere (Washington, D.C) 6, art129.

Allen CD, Macalady AK, Chenchouni Het al., 2010. A global overview of drought and heat-induced tree mortality reveals emerging climate change risks for forests. Forest ecology and management 259, 660-684.

Anderson R, 2008. A new species of flightless Hadromeropsis from the Colombian páramo (Coleoptera: Curculionidae; Entiminae; Tanymecini). Zootaxa 1879, 65.

Anderson E, Marengo J, Villalba R et al., 2012. Consequences of Climate Change for Ecosystems and Ecosystem Services in the Tropical Andes. In: Herzog S, Martinez R,, Jorgensen P,, Tiessen H, eds. Climate Change and Biodiversity in the Tropical Andes. MacArthur Fundation, Inter American Institute for Global Change Research, SCOPE, 1-19.

Anthelme F, Beck S, Ginot P, Garcia-Lino MC, Meneses RI, 2015. Ecosistemas y plantas altoandinos de la Cordillera Real: únicos y frágiles.

Anthelme F, Jacobsen D, Macek Pet al., 2014. Biodiversity patterns and continental insularity in the tropical high andes. Arctic, Antarctic, and Alpine Research 46, 811-828.

Bader MY, Rietkerk M, Bregt AK, 2007. Vegetation structure and temperature regimes of tropical alpine treelines. Arctic, Antarctic, and Alpine Research 39, 353-364.

Bader MY, Rietkerk M, Bregt AK, 2008. A simple spatial model exploring positive feedbacks at tropical alpine treelines. Arctic, Antarctic, and Alpine Research 40, 269-278.

Bani M, Rubiales D, Rispail N, 2012. A detailed evaluation method to identify sources of quantitative resistance to Fusarium oxysporum f. sp. pisi race 2 within a Pisum spp. germplasm collection. Plant pathology 61, 532-542.

Bayona G, 2018. El inicio de la emergencia en los Andes del norte: una perspectiva a partir del registro tectónico-sedimentológico del Coniaciano al Paleoceno. Revista de la Academia Colombiana de Ciencias Exactas, Físicas y Naturales 42, 364.

Beltrán Morales JC, 2018. Composición florística asociada a frailejones Espeletia spp afectados por Oidaematophorus espeletiae en el PNN Chingaza. Master thesis Thesis. Universidad de Bogotá Jorge Tadeo Lozano.

Benítez AJ, 2019. Estudio Micológico de la Rizósfera de Frailejones (Espeletiapycnophylla) en los Páramos de Paja Blanca y Morasurco-Nariño. Undergraduate thesis Thesis. Universidad de Nariño.

Bradley RS, Vuille M, Diaz HF, Vergara W, 2006. Climate change. Threats to water supplies in the tropical Andes. Science 312, 1755-1756.

Breshears DD, Knapp AK, Law DJ, Smith MD, Twidwell D, Wonkka CL, 2016. Rangeland responses to predicted increases in drought extremity. Rangelands 38, 191-196.

Buitrago SP, Vanegas LJ, Ramos C, 2015. Pérdida de pubescencia foliar y sus efectos fisiológicos en Espeletia paipana (Asterales, Asteraceae), en el departamento de Boyacá-Colombia. Unpublished.

Bulaon B, MacKenzie M, 2007. Red Fir Decline and mortality on the Stanislaus National Forest. USDA Forest Service.

Buytaert W, Cuesta-Camacho F, Tobón C, 2011. Potential impacts of climate change on the environmental services of humid tropical alpine regions. Global Ecology and Biogeography 20, 19-33.

Camacho Blanco MD, Marroquin Ramirez JE, 2014. Análisis de insectos coleoptera asociados a la afectación de frailejón Espeletia lopezii, en el páramo del costado occidental del Parque Nacional Natural El Cocuy . Malaga, Santander, Colombia: Universidad Industrial de Santander.

Camacho M, Marroquin J, 2015. Análisis de insectos Coleoptera asociados a la afectación del frailejón Espeletia lopezii. In situ, 5-15.

Chala D, Brochmann C, Psomas A et al., 2016. Good-bye to tropical alpine plant giants under warmer climates? 
Loss of range and genetic diversity in Lobelia rhynchopetalum. Ecology and evolution 6, 8931-8941.

Chow YS, Gupta VK, Nicolson SW et al., 2008. Weevils, billbugs, bark beetles, and others (coleoptera: curculionoidea). In: Capinera JL, ed. Encyclopedia of Entomology. Dordrecht: Springer Netherlands, 4184-4203.

Cifuentes Castellanos JM, 2017. Relación de variables climáticas y de uso de suelo, con la afectación de frailejones en el Páramo de Chingaza, Colombia. Master thesis Thesis. Universidad de Ciencias Aplicadas y Ambientales U.D.C.A.

Corredor NM, Delgadillo LS, Jimenez HM, 2019. Identificación de Sclerotinia sclerotiorum como fitopatogeno del frailejon Espeletia grandiflora en el Parque Nacional Natural Chingaza. Fitopatologia Colombiana 42, 20-24.

Das AJ, Stephenson NL, Davis KP, 2016. Why do trees die? Characterizing the drivers of background tree mortality. Ecology 97, 2616-2627.

Dhileepan K, Callander J, Shi B, Osunkoya OO, 2018. Biological control of parthenium ( Parthenium hysterophorus ): the Australian experience. Biocontrol science and technology 28, 970-988.

Díaz-Granados Ortiz MA, Navarrete González JD, Suárez López T, 2005. Páramos: Sensitive Hydrosystems. Revista de Ingeniería.

Dukes JS, Pontius J, Orwig D et al., 2009. Responses of insect pests, pathogens, and invasive plant species to climate change in the forests of northeastern North America: What can we predict?This article is one of a selection of papers from NE Forests 2100: A Synthesis of Climate Change Impacts on Forests of the Northeastern US and Eastern Canada. Canadian Journal of Forest Research 39, 231-248.

Florez C, Lagos LE, Betancourth C, Claudia S, 2019. Caracterización de hongos aislados de frailejón (Espeletia pycnophylla: Asteraceae) del páramo de Paja Blanca, departamento de Nariño, Colombia. Pasto: Universidad de Nariño.

Frey BR, Lieffers VJ, Hogg E(Ted), Landhäusser SM, 2004. Predicting landscape patterns of aspen dieback: mechanisms and knowledge gaps. Canadian Journal of Forest Research 34, 1379-1390.

Fuentes LS, 2019. Primer Simposio Internacional Problemas Fitosanitarios en los Páramos relacionados con el Cambio Climático: Avances y perspectivas en investigación. In: Medina M,, Varela A,, Marín C, eds. Bogotá: IAvHy PUJ, 15.

Gaitán Naranjo MA, 2018. Identificación de hongos asociados a lesiones de frailejones (Espeletia spp.) en páramos de Cundinamarca. Undergraduate thesis Thesis. Pontificia Universidad Javeriana.

Galindez E, 2019. Insectos como posibles vectores mecánicos de hongos en Espeletia pycnophylla del páramo de Paja Blanca, Nariño (Colombia). Undergraduate thesis Thesis.

Gallego J, Caicedo A, Carabalí A, Muñoz J, 2012. Feeding and oviposition behavior of Compsus viridivittatus (Coleoptera: Curculionidae) on species of citrus. Revista Colombiana de Entomología 38, 191-195.

García-Castañeda A, Díaz-Alvarado Ái, Castañeda S, 2015. Diagnóstico preliminar de microorganismos fitopatógenos asociados a plántulas de Espeletia grandiflora Humb. \& Bonpl. propagadas para su conservación ex situ. Fitopatologia Colombiana 39(1), 1-4.

González Rocha DA, 2012. Estudio preliminar de la composición de hongos endófitos en Espeletia argentea (bonpl.) en la Cuenca de la quebrada Calostros (PNN Chingaza). Undergraduate thesis Thesis. Pontificia Universidad Javeriana.

Gosik R, Sprick P, 2013. Morphology and identification of the pupae of several species of soil-dwelling broad-nosed weevils from Central Europe (Coleoptera, Curculionidae, Entiminae). Zootaxa 3731, 445-472.

Gosik R, Sprick P, Czerewko K, 2017. Morphology of the larvae of three Central European Strophosoma Billberg, 1820 (Coleoptera, Curculionidae, Entiminae) species. Deutsche Entomologische Zeitschrift 64, 27-42.

Grafton-Cradwell E, Kris G, Peña J, Mccoy C, Luck R, 2004. Diaprepes Root Weevil. UNIVERSITY OF CALIFORNIA Division of Agriculture and Natural Resources 8131, 8.

Haglund WA, Kraft JM, 1979. Fusarium oxysporum f. sp. pisi, race 6: Occurrence and distribution. Phytopathology. Halloy S, 1983. The use of convergence and divergence in the interpretation of adaptations in high mountain biota. Evolutionary Theory 6, 233-256. 
Helmer EH, Gerson EA, Baggett LS, Bird BJ, Ruzycki TS, Voggesser SM, 2019. Neotropical cloud forests and páramo to contract and dry from declines in cloud immersion and frost. Plos One 14, e0213155.

Hernández L, Fuentesa L, Fajardo G, Matthews D, 2014. A new species of Oidaematophorus (Lepidoptera: Pterophoridae) from Chingaza National Natural Park in Colombia. Tropical Lepidoptera Research.

Hofstede R, Calles J, Polanco R, Torres F, Ulloa J, 2014. Los Páramos Andinos ¿Qué sabemos? Estado de conocimiento sobre elimpacto del cambio climático en el ecosistema páramo. UICN, Quito, Ecuador.: stg-wedocs.unep.org.

Horst RK, 2013. Powdery Mildews. In: Westcott's plant disease handbook. Dordrecht: Springer Netherlands, 285-293.

Hubbard D, Millar M, 2014. Modeling resilience with applied information economics (AIE). Nairobi, Kenya: Technical Consortium, a project of the CGIAR.

Hulcr J, Stelinski LL, 2017. The ambrosia symbiosis: from evolutionary ecology to practical management. Annual Review of Entomology 62, 285-303.

IAvH, PUJ, 2019. Problemas Fito-sanitarios en los Páramos relacionados con Cambio Climático:Avances y perspectivas en la investigación (M Medina, A Varela, C Marín, Eds,). Bogotá.

Instituto Colombiano Agropecuario, 2012. Manejo fitosanitario del cultivos de citricos. ICA.

Johnson EE, Escobar LE, Zambrana-Torrelio C, 2019. An ecological framework for modeling the geography of disease transmission. Trends in Ecology \& Evolution 34, 655-668.

Kidane YO, Steinbauer MJ, Beierkuhnlein C, 2019. Dead end for endemic plant species? A biodiversity hotspot under pressure. Global ecology and conservation 19, e00670.

Kimmerer TW, Kozlowski TT, 1982. Ethylene, Ethane, Acetaldehyde, and Ethanol Production By Plants under Stress. Plant Physiology 69, 840-847.

Kirkendall LR, Biedermann PHW, Jordal BH, 2015. Evolution and Diversity of Bark and Ambrosia Beetles. In: Bark Beetles. Elsevier, 85-156.

Kitching I, Rawlins J, 1998. Lepidoptera, moths and butterflies.

Kostovcik M, Bateman CC, Kolarik M, Stelinski LL, Jordal BH, Hulcr J, 2015. The ambrosia symbiosis is specific in some species and promiscuous in others: evidence from community pyrosequencing. The ISME Journal $\mathbf{9}$, $1-13$.

Kottek M, Grieser J, Beck C, Rudolf B, Rubel F, 2006. World Map of the Köppen-Geiger climate classification updated. Meteorologische Zeitschrift 15, 259-263.

Lamanda N, Roux S, Delmotte Set al., 2012. A protocol for the conceptualisation of an agro-ecosystem to guide data acquisition and analysis and expert knowledge integration. European Journal of Agronomy 38, 104-116.

Liu WH, Dai XH, Xu JS, 2015. Influences of leaf-mining insects on their host plants: A review. Collectanea botanica 34, e005.

Llambí LD, Aranguren C, Rada F, Mora M, Ramírez L, 2019a. Primer Simposio Internacional Problemas Fitosanitarios en los Páramos relacionados con el Cambio Climático: Avances y perspectivas en investigación. In: Medina M, Varela A,, Marín C, eds. Bogotá: IAvH y PUJ, 10.

Llambí LD, Becerra MT, Peralvo M, 2019b. Construcción de una Estrategia para el Monitoreo Integrado de los Ecosistemas de Alta Montaña en Colombia. Biodiversidad en la ....

Lövei GL, Sunderland KD, 1996. Ecology and behavior of ground beetles (Coleoptera: Carabidae). Annual Review of Entomology 41, 231-256.

Luedeling E, Shepherd K, de Leeuw J et al., 2014. The application of decision analysis modelling for investment targeting. Nairobi, Kenya: Technical Consortium, a project of the CGIAR.

Luteyn JL, Churchill SP, Griffin D, Gradstein SR, 1999. Páramos: a checklist of plant diversity, geographical distribution, and botanical literature. ugeb.pw.

Maharjan S, Shrestha BB, Devkota A, Muniappan R, Jha PK, 2019. Temporal and spatial patterns of research on a globally significant invasive weed Parthenium hysterophorus L.: A bibliographic review. Crop Protection, 104832.

Manion PD, 1991. Tree Disease Concepts (2nd Edition). Englewood Cliffs, N.J: Prentice-hall. 
Martínez C, Martínez D, Varela Ramírez A, 2019. Primer Simposio Internacional Problemas Fitosanitarios en los Páramos relacionados con el Cambio Climático: Avances y perspectivas en investigación. In: Colombia: IAvH y PUJ, 16.

Mavárez J, Bézy S, Goeury T, Fernández A, Aubert S, 2018. Current and future distributions of Espeletiinae (Asteraceae) in the Venezuelan Andes based on statistical downscaling of climatic variables and niche modelling. Plant ecology \& diversity, 1-15.

McFadyen REC, 2000. Biology and Host Specificity of the Stem Galling Weevil Conotrachelus albocinereus Fiedler (Col.: Curculionidae), a Biocontrol Agent for Parthenium Weed Parthenium hysterophorus L. (Asteraceae) in Queensland, Australia. Biocontrol science and technology 10, 195-200.

Medina MM, Varela A, Martínez C, 2010. Registro de daño a los frailejones (Asteraceae: Espeletia sp.) por insectos y hongos patógenos en el PNN Chingaza (Colombia). Cespedecia 32, 67-70.

Mehrnejad MR, Meleshko JY, Korotyaev BA, 2017. Morphological description and observations on the biology of Polydrusus davatchii (Coleoptera: Curculionidae: Entiminae), a pest of pistachio trees in Iran. Biologia 72.

Moreno-Moran M, Burbano-Figueroa O, 2017. Dynamics of cotton ramulosis epidemics caused by Colletotrichum gossypii var. cephalosporioides in Colombia. European Journal of Plant Pathology 149, 443-454.

Morret P, 2005. Los coleópteros Carabidae del paramo en los Andes del Ecuador. Quito, Ecuador: Pontificia Universidad Catolica del Ecuador.

Moscatello S, Proietti S, Buonaurio Ret al., 2017. Peach leaf curl disease shifts sugar metabolism in severely infected leaves from source to sink. Plant Physiology and Biochemistry 112, 9-18.

Moslemi A, Ades PK, Groom T, Nicolas ME, Taylor PWJ, 2017. Fusarium oxysporum and Fusarium avenaceum associated with yield-decline of pyrethrum in Australia. European Journal of Plant Pathology 149, 43-56.

Muñoz-Rodríguez C, 2015. Notas ecológicas sobre la interacción entre Oidaematophorus espeletiae Hernández et al.(Pterophoridae) y Espeletia grandiflora Humb. \& Bonpl. (Asteraceae) en el Parque NacionalNatural Chingaza (Cundinamarca, Colombia). Undergraduate thesis Thesis.

Muñoz-Tobar SI, Caterino MS, 2019. The role of dispersal for shaping phylogeographical structure of flightless beetles from the Andes. PeerJ 7, e7226.

Muñoz C, 2015. Notas ecológicas sobre la interacción entre Oidaematophorus espeletiae y Espeletia grandiflora en el Parque Nacional Natural Chingaza. Unpublished.

Nabity PD, Zavala JA, DeLucia EH, 2009. Indirect suppression of photosynthesis on individual leaves by arthropod herbivory. Annals of Botany 103, 655-663.

Nykänen H, Koricheva J, 2004. Damage-induced changes in woody plants and their effects on insect herbivore performance: a meta-analysis. Oikos 104, 247-268.

Pinzón-Navarro S, Barrios H, Múrria C, Lyal CHC, Vogler AP, 2010. DNA-based taxonomy of larval stages reveals huge unknown species diversity in neotropical seed weevils (genus Conotrachelus): relevance to evolutionary ecology. Molecular Phylogenetics and Evolution 56, 281-293.

Ploetz RC, Hulcr J, Wingfield MJ, de Beer ZW, 2013. Destructive tree diseases associated with ambrosia and bark beetles: black swan events in tree pathology? Plant disease 97, 856-872.

Ploetz R, Kendra P, Choudhury Ret al., 2017. Laurel wilt in natural and agricultural ecosystems: understanding the drivers and scales of complex pathosystems. Forests $8,48$.

Ponce D, 2019. Primer Simposio Internacional Problemas Fitosanitarios en los Páramos relacionados con el Cambio Climático: Avances y perspectivas en investigación. In: Medina M,, Varela A,, Marín C, eds. Bogotá: IAvHy PUJ, 17.

Prieto R, 2017. Lesiones de frailejones (Espeletia sp.) y potenciales hongos fitopatógenos asociados, en los páramos de Chingaza y Cruz Verde. Undergraduate thesis Thesis. Pontiificia Universidad Javeriana.

Raftery AE, Zimmer A, Frierson DMW, Startz R, Liu P, 2017. Less than $2^{\circ} \mathrm{C}$ warming by 2100 unlikely. Nature climate change 7, 637-641.

Ramamurthy VV, 2007. Faunistic, ecological, biogeographical and phylogenetic aspects of Coleoptera as gall-inducers and associates in plant galls in the Orient and eastern Palearctic. Oriental insects 41, 93-119. 
Raman A, 2011. Morphogenesis of insect-induced plant galls: facts and questions. Flora - Morphology, Distribution, Functional Ecology of Plants 206, 517-533.

Ranger CM, Biedermann PHW, Phuntumart V et al., 2018. Symbiont selection via alcohol benefits fungus farming by ambrosia beetles. Proceedings of the National Academy of Sciences of the United States of America 115, 4447-4452.

Ranger CM, Reding ME, Persad AB, Herms DA, 2010. Ability of stress-related volatiles to attract and induce attacks by Xylosandrus germanus and other ambrosia beetles. Agricultural and forest entomology 12, 177-185.

Ranger CM, Reding ME, Schultz PB, Oliver JB, 2012. Ambrosia beetle (Coleoptera: Curculionidae) responses to volatile emissions associated with ethanol-injected Magnolia virginiana. Environmental Entomology 41, 636-647.

Reed SE, Juzwik J, English JT, Ginzel MD, 2015. Colonization of artificially stressed black walnut trees by ambrosia beetle, bark beetle, and other weevil species (coleoptera: curculionidae) in indiana and missouri. Environmental Entomology 44, 1455-1464.

Rehm EM, Feeley KJ, 2015. The inability of tropical cloud forest species to invade grasslands above treeline during climate change: potential explanations and consequences. Ecography 38, 1167-1175.

Reinoso-Flórez G, Villa-Navarro F, Losada-Prado S, 2016. Artropofauna epigea del páramo Estambul (Tolima), Colombia. Biota 17, 39-51.

Riley MB, Williamson MR, Maloy O, 2002. Plant disease diagnosis. Plant Health Instructor.

Rivera-Ospina D, Rodríguez-Murcia CE, 2011. Guía divulgativa de criterios para la delimitación de páramos de Colombia.

Rubel F, Brugger K, Haslinger K, Auer I, 2017. The climate of the European Alps: Shift of very high resolution Köppen-Geiger climate zones 1800-2100. Meteorologische Zeitschrift 26, 115-125.

Ruiz D, Moreno HA, Gutiérrez ME, Zapata PA, 2008. Changing climate and endangered high mountain ecosystems in Colombia. The Science of the Total Environment 398, 122-132.

Rundel PW, Smith AP, Meinzer FC(Eds.), 1994. Tropical alpine environments: plant form and function. Cambridge University Press.

Sack L, Holbrook NM, 2006. Leaf hydraulics. Annual review of plant biology 57, 361-381.

Salazar González C, Betancourth García C, Baca Gamboa AE et al., 2019. Primer Simposio Internacional Problemas Fitosanitarios en los Páramos relacionados con el Cambio Climático: Avances y perspectivas en investigación. In: Bogotá: IAvHy PUJ, 21.

Salinas C, Fuentes LS, Hernández L, 2013. Caracterización de los lepidópteros fitófagos asociados a la herbivoría de frailejones en la microcuenca de la quebrada Calostros del Parque Nacional Natural Chingaza. Revista Mutis 3, 22.

Shepherd K, Hubbard D, Fenton N, Claxton K, Luedeling E, de Leeuw J, 2015. Policy: Development goals should enable decision-making. Nature 523, 152-154.

Shepherd K, Luedeling E, de Leeuw J, Rosenstock T, 2014. A novel decision analysis and risk assessment framework for improving agro-ecosystem interventions. Nairobi, Kenya: Technical Consortium, a project of the CGIAR.

Sklenář P, Hedberg I, Cleef AM, 2014. Island biogeography of tropical alpine floras. Journal of biogeography 41, 287-297.

Skuhrovec J, Volovnik S, Gosik R, Stejskal R, Trnka F, 2019. Cleonis pigra (Scopoli, 1763) (Coleoptera: Curculionidae: Lixinae): Morphological Re-Description of the Immature Stages, Keys, Tribal Comparisons and Biology. Insects 10.

Smith-McKenna EK, Malanson GP, Resler LM, Carstensen LW, Prisley SP, Tomback DF, 2014. Cascading effects of feedbacks, disease, and climate change on alpine treeline dynamics. Environmental Modelling \& Software 62, 85-96.

Valverde RA, Sabanadzovic S, Hammond J, 2012. Viruses that Enhance the Aesthetics of Some Ornamental Plants: Beauty or Beast? Plant disease 96, 600-611.

Vanderpool D, Bracewell RR, McCutcheon JP, 2018. Know your farmer: Ancient origins and multiple 
independent domestications of ambrosia beetle fungal cultivars. Molecular Ecology 27, 2077-2094.

Varela A, 2014. Limitantes en la restauración ecológica: estudio de caso de las afecciones por patógenos en el Parque Nacional Natural Chingaza. In: Cabrera M, Ramírez W, eds. Restauración ecológica de los páramos de Colombia: Transformación y herramientas para su conservación. Bogotá, Colombia, 212-227.

Varela A, 2019. Primer Simposio Internacional Problemas Fitosanitarios en los Páramos relacionados con el Cambio Climático: Avances y perspectivas en investigación. In: Medina M,, Varela A,, Marín C, eds. Bogotá: IAvHy PUJ, 14.

Vargas HA, Parra LE, 2005. Una nueva especie de Lioptilodes Zimmerman (Lepidoptera: Pterophoridae) de Chile. Neotropical entomology 34.

Walz U, 2011. Landscape Structure, Landscape Metrics and Biodiversity. Living Reviews in Landscape Research 5.

Wang W, Peng C, Kneeshaw DD, Larocque GR, Luo Z, 2012. Drought-induced tree mortality: ecological consequences, causes, and modeling. Environmental Reviews 20, 109-121.

Zhou S, Lou Y-R, Tzin V, Jander G, 2015. Alteration of plant primary metabolism in response to insect herbivory. Plant Physiology 169, 1488-1498.

Zimmer A, Meneses RI, Rabatel A, Soruco A, Dangles O, Anthelme F, 2017. Time lag between glacial retreat and upward migration alters tropical alpine communities. Perspectives in Plant Ecology, Evolution and Systematics. 